\title{
LA EJECUCIÓN DE SENTENCIAS DEL TRIBUNAL DE JUSTICIA COMO RESPONSABILIDAD CONSTITUCIONAL COMPARTIDA: LUCES Y SOMBRAS
}

\author{
BEATRIZ TOMÁS MALLÉN \\ Profesora Titular de Derecho Constitucional \\ Universitat Jaume I
}

\section{SUMARIO}

I. Cuestiones preliminares: la dimensión constitucional europea de la ejecución de sentencias del TJUE. II. La general vis expansiva de la jurisprudencia del TJUE: impregnación transversal de la actividad jurisdiccional nacional. III. La concreta ejecución de sentencias del TJUE por vía judicial. IV. La evolución de la normativa nacional propiciada por la jurisprudencia del TJUE. V. La concreta ejecución de sentencias del TJUE por vía ejecutiva y legislativa. VI. Reflexiones finales: la ejecución de sentencias del TJUE como optimización del ordenamiento jurídico interno.

\section{CUESTIONES PRELIMINARES: LA DIMENSIÓN CONSTITUCIONAL EUROPEA DE LA EJECUCIÓN DE SENTENCIAS DEL TJUE}

Con carácter introductorio cabe observar que, pese a la no asunción de la terminología constitucional (en un plano formal) en el Derecho primario, ni siquiera tras la última gran reforma operada mediante el Tratado de Lisboa (sobre la cual se ha apuntado que sí reflejaría una «Constitución material» en cierta medida o habría procedido a una especie de «rescate sustancial» de importantes aspectos del frustrado Tratado por el que se establecía una Constitución para Europa de 2004) ${ }^{1}$, el Tribunal de Justicia de la Unión Europea pasa por erigirse en la institución

1 F. Aldecon Luzarraga, y M. Guinea Llorente, «El rescate sustancial de la Constitución Europea a través del Tratado de Lisboa: la salida del laberinto», Documento de trabajo n. ${ }^{0}$ 9/2008, Real Instituto Elcano. 
más relevante, pese a algunos vaivenes, del creciente proceso de constitucionalización de Europa ${ }^{2}$.

En efecto, sin perjuicio de la inexistencia formal de unos Estados Unidos de Europa y de una Constitución Europea, lo cierto es que el Tribunal de Justicia de la Unión Europea (compuesto desde 2016 por dos jurisdicciones, esto es, el Tribunal de Justicia — TJUE — y el Tribunal General —el Tribunal de la Función Pública ha desaparecido, al integrarse sus miembros en el segundo-) se ha ido paulatinamente configurando como un «Tribunal Constitucional Europeo». Y ello no tanto por declaraciones más o menos formales o simbólicas que haya podido incluir en algunos pronunciamientos subrayados por la doctrina ${ }^{3}$, ni tan sólo por una construcción dogmática de los derechos fundamentales (sin una base habilitante o un catálogo amplio y «visible» en el seno de la UE hasta la incorporación de la Carta de los Derechos Fundamentales mediante el Tratado de Lisboa $)^{4}$ a través de una significativa obra pretoriana, sino más sencillamente por las competencias de índole constitucional que ya se le atribuyeron en los Tratados originarios y que se han ido consolidando mediante sus reformas 5 .

Desde esta misma perspectiva, se ha subrayado igualmente que, desde los orígenes de la integración europea, la «Europa del Derecho» que conformaron las Comunidades Europeas en virtud de los Tratados originarios y sus reformas ha tenido al Tribunal de Justicia como institución menos aquejada del famoso déficit democrático, a diferencia de las instituciones políticas, señaladamente el Parlamento Europeo (PE). De hecho, aunque se haya puesto lógicamente el acento en la Comisión Europea como institución más original y motor de la construcción europea, ha sido el TJUE el que ha asegurado la evolución y afirmación de la UE como «Comunidad de Derecho», con mayor vocación federal (a rebufo de la Declaración Schuman de 1950) y con una impregnación de una tendencial «Europa Constitucional».

2 M. A. Alegre Martínez, y L. Jimena Quesada, Fundamentos constitucionales de la Unión Europea, Biblioteca Nueva, 2006, p. 31: «A la vista del carácter autónomo del ordenamiento comunitario y de las características de los Tratados (cuyo carácter constitucional ha sido afirmado por el Tribunal de Justicia de Luxemburgo a partir de la sentencia de 23 de abril de 1986, caso Partido Ecologista-Los Verdes contra el Parlamento Europeo), no parece haber obstáculos insalvables para coincidir con quienes afirman que la UE tiene ya una constitución material».

3 M. L. Fernández Esteban, «La noción de Constitución europea en la jurisprudencia del Tribunal de Justicia de las Comunidades Europeas», Revista Española de Derecho Constitucional, n. . 40, 1994, pp. 241-289. Más recientemente, el amplio análisis de L. Gordillo Pérez, y G. MArTinico, Historias del país de las hadas. La jurisprudencia constitucionalizadora del Tribunal de Justicia, Civitas/Thomson Reuters, Madrid, 2015: ambos autores conciben la constitucionalización como «federalización» y como «humanización» del Derecho europeo.

4 F. Balaguer Callejón, «La Constitución europea tras el Consejo Europeo de Bruselas y el Tratado de Lisboa», Revista de Derecho Constitucional Europeo, n. ${ }^{\circ}$ 8, 2007, p. 26: «La especificación del 'carácter jurídico vinculante' de la Carta 'que tendrá el mismo valor jurídico que los Tratados' elimina cualquier duda sobre su naturaleza constitucional».

5 Como señala A. PACE, «no es difícil prever de modo realista que la vía de la unificación europea será la trazada dúctilmente por su jurisprudencia [la del TJUE] y no la, traumática, de la adopción de un constitución documental y prescriptiva», «¿Para qué sirve la Carta de los Derechos Fundamentales de la Unión Europea?», Teoría y Realidad Constitucional, n. ${ }^{\circ}$ 7, 2001, p. 186. 
Es por ello que resulta congruente sostener que la ejecución de sentencias del TJUE representa, de alguna manera, el exponente más emblemático de la dimensión constitucional de la $\mathrm{UE}^{6}$, puesto que refleja con contundencia la coherencia con el principio «pacta sunt servanda» o, más restringidamente, el de lealtad comunitaria; o, correlativamente, la expresión más trascendental de la clásica transferencia de «derechos soberanos» articulada a nivel constitucional interno.

Así, cabría entender que el precepto constitucional español utilizado como base habilitante para la integración europea, esto es, el art. 93 de la Constitución española (CE), se refiere correctamente a la ejecución de sentencias del TJUE cuando alude a «las resoluciones emanadas de los organismos internacionales o supranacionales titulares de la cesión», debiendo advertirse no obstante la paradoja consistente en reconducir esa posible ejecución a los Poderes Legislativos y Ejecutivo («a las Cortes o al Gobierno, según los casos»), omitiendo inexplicablemente al Poder Judicial. Dicha omisión (junto a la paralela laguna referente a la Asambleas Legislativas y a los Gobiernos de las Comunidades Autónomas ${ }^{7}$ ) resulta criticable, puesto que la mayor parte de las resoluciones del TJUE derivan de cuestiones prejudiciales planteadas por los órganos jurisdiccionales nacionales y, en consecuencia, sin perjuicio del alcance más genérico de la sentencia del Tribunal de Luxemburgo (susceptible de exigir una eventual modificación normativa nacional) ${ }^{8}$, su ejecución concreta vendrá de la mano de las jurisdicciones domésticas intervinientes.

\section{LA GENERAL VIS EXPANSIVA DE LA JURISPRUDENCIA DEL TJUE: IMPREGNACIÓN TRANSVERSAL DE LA ACTIVIDAD JURISDICCIONAL NACIONAL}

\section{Ante la Jurisdicción Ordinaria}

Suele calificarse al juez nacional como el juez comunitario o europeo por excelencia ${ }^{9}$ porque, salvo cuando albergue dudas interpretativas sobre el Derecho de la UE conducentes a la formulación de cuestiones prejudiciales, debe

6 Se trata de una cuestión que goza de «alcance constitucional», como hace tiempo ya observó J. V. LouIs, «Los efectos de las sentencias del Tribunal de Justicia de las Comunidades Europeas», Revista de Instituciones Europeas, vol. 10, n. ${ }^{\circ} 1,1983$, p. 9.

7 Dicha laguna se aprecia con la sola lectura del segundo inciso del art. 93 CE: «Mediante ley orgánica se podrá autorizar la celebración de tratados por los que se atribuya a una organización o institución internacional el ejercicio de competencias derivadas de la Constitución. Corresponde a las Cortes Generales o al Gobierno, según los casos, la garantía del cumplimiento de estos tratados y de las resoluciones emanadas de los organismos internacionales o supranacionales titulares de la cesión».

8 Sobre el alcance erga omnes de dichas sentencias del TJUE, léase M. CiEnFuEGos MATEO, Las sentencias prejudiciales del Tribunal de Justicia de las Comunidades Europeas en los Estados miembros: estudio de la interpretación prejudicial y de su aplicación por los jueces y magistrados nacionales, Bosch, Barcelona, 1998.

9 D. Ruiz-Jarabo Colomer, El juez nacional como juez comunitario, Civitas, Madrid, 1993. 
inspirarse con naturalidad en la jurisprudencia del TJUE. El propio TC, tras sostener repetidamente que el Derecho de la UE no constituye canon de constitucionalidad, ha afirmado consecuentemente que «ni la Constitución ni ninguna ley orgánica han atribuido a este Tribunal competencia para conocer de la adecuación del ordenamiento interno al comunitario, por lo que dicha competencia debe entenderse comprendida dentro de la genérica y privativa del Poder Judicial (art. 117.3). Así lo declaramos en la STC 64/1991: “Tiene razón el Abogado del Estado al decir que no corresponde al Tribunal Constitucional controlar la adecuación de la actividad de los poderes públicos nacionales al Derecho comunitario europeo. Este control compete a los órganos de la jurisdicción ordinaria, en cuanto aplicadores que son del ordenamiento comunitario, y, en su caso, al Tribunal de Justicia de las Comunidades Europeas a través del recurso por incumplimiento (art. 170 TCEE)” " (STC 213/1994, de 14 de julio, FJ 3$)^{10}$.

Por lo demás, no faltan ejemplos en la legislación española en donde se resalta un aspecto evidente y lógico, a saber, que los órganos jurisdiccionales nacionales han de hacerse eco de las fuentes del Derecho de la UE, tanto de la normativa como de la jurisprudencia comunitarias. Así en el Preámbulo de la LO 1/2015, de 30 de marzo, por la que se modifica la LO 10/1995, de 23 de noviembre, del Código Penal, se recuerda que «la sustitución de las penas de prisión por la medida de expulsión del territorio nacional en el caso de delitos cometidos por un ciudadano europeo, se contempla con carácter excepcional, reservándose a aquellos supuestos en los que su autor representa una amenaza grave para el orden público o la seguridad pública, en atención a los criterios recogidos en la Directiva 2004/38/CE del Parlamento Europeo y del Consejo, de 29 de abril de 2004, relativa al derecho de los ciudadanos de la Unión y de los miembros de sus familias a circular y residir libremente en el territorio de los Estados miembros, así como en la Jurisprudencia del Tribunal de Justicia de la Unión Europea, que deberán ser tenidos en cuenta por los jueces $y$ tribunales en la interpretación y aplicación del precepto correspondiente» ${ }^{11}$.

A decir verdad, la evidencia y la lógica no siempre han imperado en dicho ámbito, como lo acredita que haga apenas sólo un lustro que se haya incorporado explícitamente al orden jurisdicción social la obligación de considerar como referente ineludible a efectos casacionales las sentencias del TJUE; lo cual, obviamente, comporta una exigencia de nuestro sistema de fuentes y de nuestro sistema de derechos y libertades, como apunta el Preámbulo de la Ley 36/2011, de 10 de octubre, reguladora de la jurisdicción social ${ }^{12}$. En un sentido parecido, la Ley

$10 \mathrm{O}$, dicho de otro modo, «la tarea de garantizar la recta aplicación del Derecho comunitario europeo por los poderes públicos nacionales es una cuestión de carácter infraconstitucional» (entre otras muchas, SSTC 41/2002, 120/2012, 135/2012, 237/2012, 239/2012, 19/2013, 51/2013, 64/2013, 183/2014, 44/2015 o 233/2015).

11 La cursiva es nuestra.

12 En el Preámbulo de dicha ley puede leerse: «Además, no se han venido admitiendo, como doctrina de contradicción o contraste a efectos de este recurso, las sentencias dictadas por el Tribunal 
34/2015, de 21 de septiembre, de modificación parcial de la Ley 58/2003, de 17 de diciembre, General Tributaria, señala en su Preámbulo que «debido a la especial incidencia que en el ámbito de la fiscalidad tiene el Derecho de la Unión Europea, así como las sentencias del Tribunal de Justicia de la Unión Europea, se procede a la introducción de mecanismos y preceptos en la Ley 58/2003, de 17 de diciembre, General Tributaria, para incrementar el grado de integración legal y efectividad del Derecho de la Unión Europea» ${ }^{13}$.

En ocasiones, el propio TJUE ha apelado explícitamente a los órganos jurisdiccionales internos, incluso en el fallo, como por ejemplo la Sentencia SIMAP (asunto C-303/98, Sindicato de Médicos de Asistencia Pública, Simap, contra Conselleria de Sanidad y Consumo de la Generalitat Valenciana) de 3 de octubre de 2000 (asunto C-303/98) sobre tiempo de trabajo y medidas de seguridad y salud de los trabajadores en el trabajo ${ }^{14}$.

En cualquier caso, cabría adicionalmente distinguir (tal como haremos más abajo al abordar la ejecución por vía de intervención normativa) entre una ejecución judicial «fuerte»y una ejecución judicial «débil». La primera modalidad se dará en el caso de la asunción por el órgano jurisdiccional de la sentencia del TJUE resolutoria de una cuestión prejudicial. La segunda permite un cierto margen de discrecionalidad judicial en el ámbito interno a la hora de dotar de pleno sentido en el caso concreto a nociones acuñadas por el Tribunal de Luxemburgo y a ella se refiere, por ejemplo, la Ley 29/2009, de 30 de diciembre, por la que se modifica el régimen legal de la competencia desleal y de la publicidad para la mejora de la protección de los consumidores y usuarios ${ }^{15}$.

Constitucional, por los órganos jurisdiccionales de ámbito supranacional en materia de derechos fundamentales, ni por el Tribunal de Justicia de la Unión Europea en interpretación del Derecho comunitario, a pesar de la vinculación de los órganos jurisdiccionales a las anteriores, en aplicación, respectivamente, del apartado 1 del artículo 5 de la Ley Orgánica 6/1985, de 1 de julio, del Poder Judicial, del apartado 2 del artículo 10 y del apartado 1 del artículo 96 de la Constitución». En coherencia con ello, el art. 219.2 in fine de la Ley (al regular el recurso de casación para la unificación de doctrina) dispone que «podrá invocarse la doctrina establecida en las sentencias del Tribunal de Justicia de la Unión Europea en interpretación del derecho comunitario».

13 Y concreta lo siguiente: «En relación con la legitimación de los órganos económico-administrativos para promover cuestiones prejudiciales ante el TJUE, tal y como el mismo ha admitido, como mera manifestación de la primacía y efecto directo del Derecho de la Unión Europea, se establecen normas de procedimiento dirigidas a regular tal actividad, estableciéndose, además, que la interposición de tales cuestiones prejudiciales suspenderá el procedimiento económico-administrativo, así como el cómputo del plazo de prescripción».

$14 «(. .$.$) Corresponde al órgano jurisdiccional nacional, de conformidad con el Derecho interno, resol-$ ver la cuestión de si la normativa nacional sobre trabajo nocturno de los trabajadores sujetos a una relación de Derecho privado puede aplicarse a los médicos de Equipos de Atención Primaria, que están sujetos a una relación de Derecho público».

15 En su Preámbulo se señala que «el concepto de «consumidor medio» ha sido acuñado por la jurisprudencia del Tribunal de Justicia de las Comunidades Europeas no en términos estadísticos, sino como la reacción típica del consumidor normalmente informado, razonablemente atento y perspicaz, teniendo en cuenta los factores sociales, culturales y lingüísticos. En consecuencia, no es un término que la ley haya de definir, sino que han de ser los tribunales los que van a efectuar su concreción en cada caso concreto». 


\section{Ante la Jurisdicción Constitucional}

Como parecía lógico, el TC se inspiró de la jurisprudencia del TJUE ya desde la segunda mitad de la década de los años ochenta del siglo pasado a partir de la adhesión de España a las Comunidades Europeas. Naturalmente, aunque los derechos fundamentales no estuvieran consagrados en la UE en un catálogo amplio y sistemático hasta la vigencia del Tratado de Lisboa el 1 de diciembre de 2009 (y, con él, de la Carta de los Derechos Fundamentales), la clásica jurisprudencia pretoriana del TJUE en dicha materia (basada en los principios generales del Derecho comunitario) no dejaba de proyectar una fuerza expansiva y transversal que debía inspirar la propia jurisprudencia constitucional española, ya fuera en procesos de amparo constitucional, ya en otro tipo de procedimientos sustanciados ante el TC. La proyección de esa fuerza expansiva y transversal no debe reducirse - si acaso al contrario- por el cambio de «lógica» en el proceder del TJUE: antes lógica de la creatividad, ahora de la interpretación del Derecho escrito $^{16}$.

Un buen ejemplo de ello lo suministra la STC 132/1989, de 18 de julio, sobre el alcance de posibles diferencias de trato entre agricultores españoles y otros nacionales de los Estados miembros ${ }^{17}$. Así, en el FJ 12 se trae explícitamente a colación una sentencia del Tribunal de Luxemburgo [ «como ha dicho el Tribunal de Justicia de las Comunidades Europeas (Asunto Boussac, 22/1980, Sentencia de octubre de 1980)»] para enfocar la no discriminación por razón de nacionalidad, tras indicar que pese a no poder ser utilizado el Derecho primario de la UE (a la sazón, «el art. 7 del Tratado de Roma») «como parámetro directo de constitucionalidad», pudiera admitirse que un precepto comunitario, de acuerdo al art. 10.2 CE, sirviera de pauta para la interpretación de la propia Constitución (en este supuesto, de su art. 14) ${ }^{18}$.

16 En palabras de P. Cruz Villalón, «Para el TJUE esto significa esencialmente sustituir la lógica de la creatividad que fluye de la noción de principios generales por una lógica de la interpretación del Derecho escrito, la interpretación de la Carta de los Derechos Fundamentales de la Unión», "The 'added value' of the Charter 'in relation to' the European Convention on Human Rights», en el colectivo Igualdad y democracia: el género como categoría de análisis jurídico. Estudios en Homenaje a la Profesora Julia Sevilla, Corts Valencianes, Valencia, 2014 p. 214.

17 Recursos de inconstitucionalidad 961/1985, 174/1987, 398/1987, 407/1987, 410/1987 y 425/1987, y conflicto positivo de competencia 504/1987 (acumulados). Promovidos, respectivamente, por el Presidente del Gobierno, por 70 Diputados, por la Generalidad de Cataluña, por el Consejo de Gobierno de la Diputación Regional de Cantabria, por el Gobierno Vasco, por 57 Diputados y por el Gobierno de la Nación: el primero, contra la Ley del Parlamento de Cataluña 18/1985, de 23 de julio, de Cámaras Profesionales Agrarias; los cinco siguientes, contra la Ley 23/1986, de 24 de diciembre, por la que se establecen las bases del Régimen Jurídico de las Cámaras Agrarias, y el último, promovido por el Gobierno de la Nación, contra el Decreto 32/1987, de la Junta de Galicia, por el que se autoriza la adquisición del derecho a usar los inmuebles propiedad de las Cámaras Agrarias Gallegas.

18 «(...) el art. 7 del Tratado de Roma no puede ser utilizado como parámetro directo de constitucionalidad. Pero aun de admitirse — por la naturaleza de su contenido, dada la conexión que la jurisprudencia comunitaria le ha dado con la protección de los derechos humanos sobre todo en materia de libre circulación 
Por cierto, en la LO 1/2008, de 30 de julio, de autorización de la ratificación del Tratado de Lisboa, se apela a la fuerza del art. 10.2 $\mathrm{CE}^{19}$. A la vista de ello, la propia jurisprudencia constitucional ha añadido congruentemente que la referencia a los tratados y acuerdos internacionales del art. 10.2 incluye «los Tratados de la Unión Europea y la Carta de derechos fundamentales de la Unión Europea, que tiene la misma eficacia jurídica vinculante que los Tratados, en virtud de lo dispuesto en el Tratado de Lisboa de 13 de diciembre de 2007» (por todas, STC 41/2013, de 14 de febrero, FJ 2).

Por añadidura, la natural inspiración o impregnación trasversal, receptora de la jurisprudencia comunitaria europea por parte del TC, se ha visto llamada a jugar un papel cada vez más fuerte, de modo que la referida posición sobre la exclusión del Derecho de la UE del canon de constitucionalidad (reconduciendo el control de la adecuación del ordenamiento doméstico al ordenamiento comunitario europeo a los órganos jurisdiccionales ordinarios) no deja de ser artificiosa en algunos casos, planteando paradójicamente más problemas (de compatibilidad del canon constitucional y del estándar europeo) que los que resuelve. Los votos particulares discrepantes formulados a la STC 147/1996, de 19 de septiembre, ponen de manifiesto con creces dicha problemática ${ }^{20}$ : en el primero (suscrito por Carles Viver Pi-Sunyer, al que se adhiere Vicente Gimeno Sendra) la discrepancia se basa precisamente en que la mayoría del TC se aparta de la jurisprudencia del TJUE ${ }^{21}$; en el segundo (firmado por Julio Diego González Campos) se reprocha que «aun cuando la Sentencia se apoye en una jurisprudencia consolidada del Tribunal sobre las relaciones entre el Derecho comunitario y la Constitución, en el presente caso la radical exclusión del primero supone, a mi entender, que la solución a la que se ha llegado en el fallo sea, en buena medida, tan inapropiada como irreal», trayéndose a colación asimismo una sentencia del TJUE para concluir que «de ello resulta claramente que en el presente caso existía un conflicto entre las previsiones de la norma española de transposición de la Directiva comunitaria y esta última. Conflicto que aun cuando el Tribunal Constitucional no esté llamado a resolverlo, al menos, a mi entender, no podía ignorar».

de personas - que el precepto comunitario, de acuerdo al art. 10.2 C.E., pudiera servir de pauta para la interpretación del art. 14 de la misma (...)».

19 Art. 2 (Carta de los Derechos Fundamentales de la Unión Europea) de dicha Ley: «A tenor de lo dispuesto en el párrafo segundo del artículo 10 de la Constitución española y en el apartado 8 del artículo 1 del Tratado de Lisboa, las normas relativas a los derechos fundamentales y a las libertades que la Constitución reconoce se interpretarán también de conformidad con lo dispuesto en la Carta de los Derechos Fundamentales publicada en el «DOUE» de 14 de diciembre de 2007, cuyo texto íntegro se reproduce a continuación: (...)».

20 Conflicto positivo de competencia 329/1989. Promovido por el Consejo Ejecutivo de la Generalidad de Cataluña en relación con el Real Decreto 1.122/1988, de 23 de septiembre, del Ministerio de Relaciones con las Cortes y de la Secretaría del Gobierno, por el que se aprueba la Norma General de Etiquetado, Presentación y Publicidad de los Productos Alimenticios Envasados.

21 Concretamente, se citan en el voto particular «las Sentencias del Tribunal de Justicia de las Comunidades Europeas de 18 de junio de 1991, asunto C-369/1989, Piageme; la de 9 de agosto de 1994, asunto C-51/1993, Meyhui y, muy especialmente, la de 12 de octubre de 1995, asunto 85/1994, Piageme II». 
Esa línea crítica ha llevado en la práctica al TC a matizar su posición, y así cabe constatarlo en pronunciamientos posteriores como la STC 208/1999, de 11 de noviembre ${ }^{22}$, en cuyo FJ 4 se sostiene que la dimensión puramente interna y la dimensión comunitaria europea de la protección de la libre competencia son «interdependientes» y se articulan «en unos términos que han sido precisados tanto por la jurisprudencia del Tribunal de Justicia de las Comunidades Europeas (Sentencias de 13 de febrero de 1969, asunto 14/68, Walt Wilhem y otros c. Bundeskartellamt y de 10 de julio de 1980, asunto 253/78, Fiscal de la República c. Bruno Guiry y Guerlain, S. A., entre otras decisiones) como por las disposiciones de los Reglamentos CEE 17/1962 y 1310/1997, del Consejo». De lo cual se deriva que «no cabe ignorar que la propia interpretación del sistema de distribución competencial entre el Estado y las Comunidades Autónomas tampoco se produce en el vacío (STC 102/1995, FJ 5) y, por tanto, no sólo es útil sino también obligado para su correcta aplicación el prestar atención al modo en que una determinada institución jurídica ha sido configurada por la normativa comunitaria» $^{23}$.

\section{LA CONCRETA EJECUCIÓN DE SENTENCIAS DEL TJUE POR VÍA JUDICIAL}

1. Luces: Normal ejecución directa por vía de colaboración judicial (cuestiones prejudiciales) e incontrovertida vigencia de la primacía y el efecto directo del Derecho de la UE

Como el TC, también el Tribunal Supremo (TS) y la Audiencia Nacional (AN), seguramente imbuidos de un espíritu «autorreferencial» merced a su alta posición, rehusaron durante cierto tiempo someter al Tribunal de Luxemburgo sus posibles dudas interpretativas sobre el Derecho de la UE. Sin embargo, los demás órganos jurisdiccionales ordinarios actuaron tempranamente con un espíritu de mayor apertura hacia los retos planteados por la integración europea, acudiendo sin recelos, e incluso con cierto entusiasmo, al TJUE para recabar su colaboración prejudicial. Por tal motivo, nos limitaremos en este apartado a ilustrar el positivo cambio de actitud por parte del TS y de la AN con algunos ejemplos.

En cuanto al órgano supremo de la jurisdicción ordinaria, se vio enfrentado a dos asuntos en los que se impugnaban diversas disposiciones del Real Decreto 1720/2007, de 21 de diciembre, por el que se aprueba el Reglamento de desarrollo

22 Recursos de inconstitucionalidad 2.009/1989 y 2.027/1989 (acumulados). Promovidos, respectivamente, por el Gobierno Vasco y el Consejo Ejecutivo de la Generalidad de Cataluña respecto a la Ley 16/1989, de 17 de julio, de Defensa de la Competencia.

23 Léase asimismo la más reciente STC 84/2015, de 30 de abril, FJ 6. 
de la LO 15/1999, de 13 de diciembre, de Protección de Datos de Carácter Perso$\mathrm{nal}^{24}$. Ambos se resolvieron por la Sala de lo Contencioso-Administrativo del TS mediante sendas Sentencias de fecha 15 de julio de 2010, que fallaron la anulación de algunas de esas disposiciones, al tiempo que se dejó imprejuzgada la impugnación común en ambos recursos del art. 10.2.a) y b) del citado Reglamento al plantear la cuestión prejudicial ante el TJUE ${ }^{25}$.

Lo interesante del proceder del TS, en términos de tutela judicial efectiva, radica en no haber suspendido la resolución global de ambos recursos, sino solamente la impugnación que le suscitó dudas interpretativas del Derecho de la UE determinantes del fallo [la del citado art. 10.2 a) y b) del Real Decreto 1720/2007], lo que además fue secundado por una rápida resolución por parte del TJUE mediante Sentencia de 24 de noviembre de 2011 (ASNEF y FECEMD, asuntos acumulados C-468 y C-469). Y, acto seguido, el propio TS asumió lógicamente el carácter vinculante de la interpretación efectuada en la STJUE de 24 de noviembre de $2011^{26}$, a través de sendas Sentencias de 8 de febrero de $2012^{27}$.

Nos encontramos, pues, ante una normal y natural ejecución directa de una Sentencia del TJUE a través de la colaboración propiciada por el planteamiento prejudicial del TS que, a mayor abundamiento, aportó un doble valor añadido, a saber: en cuanto al fondo, el pronunciamiento del TJUE estuvo inspirado por la mayor protección de los derechos fundamentales (apartados 40 a 43) 28 ; y, desde

24 Recursos contencioso-administrativos n. ${ }^{\circ}$ 23/2008 interpuesto por la Asociación Nacional de Establecimientos Financieros de Crédito (ASNEF) y n. ${ }^{\circ}$ 25/2008 formulado por la Federación de Comercio Electrónico y Marketing Directo (FECEMD).

25 Particularmente, la Sentencia sobre el recurso n. ${ }^{\circ} 23 / 2008$ concluyó la inadmisibilidad del recurso en cuanto a diversas disposiciones (arts. 45.1.b), 46.2.b) y c), y 3, 47, y 49.1 y 4) del Real Decreto 1720/2007, la anulación de otras [arts. 11, 18, 38.1 (en parte), 38.2 y 123.2] y dejar imprejuzgada la impugnación del art. 10.2.a) y b) por planteamiento de la cuestión prejudicial ante el TJUE y hasta el pronunciamiento de éste; mientras que en la Sentencia relativa al recurso n. ${ }^{\circ}$ 25/2008 se falló la indamisibilidad del recurso respecto de algunos preceptos (arts. 38, 41 y 42), la anulación del art. 18 y dejar asimismo imprejuzgada (por la misma razón de prejudicialidad) la impugnación del art. 10.2.a) y b).

26 Este es el contenido del fallo: «1) El artículo 7, letra f), de la Directiva 95/46/CE del Parlamento Europeo y del Consejo, de 24 de octubre de 1995, relativa a la protección de las personas físicas en lo que respecta al tratamiento de datos personales y a la libre circulación de estos datos, debe interpretarse en el sentido de que se opone a una normativa nacional que, para permitir el tratamiento de datos personales necesario para la satisfacción del interés legítimo perseguido por el responsable del tratamiento o por el tercero o terceros a los que se comuniquen los datos, exige, en el caso de que no exista consentimiento del interesado, no sólo que se respeten los derechos y libertades fundamentales de éste, sino además que dichos datos figuren en fuentes accesibles al público, excluyendo así de forma categórica y generalizada todo tratamiento de datos que no figuren en tales fuentes. 2) El artículo 7, letra f), de la Directiva 95/46 tiene efecto directo».

27 El fallo de ambas Sentencias del TS es idéntico (con la única lógica variación de la parte demandante), en el sentido de «extender el pronunciamiento de estimación del recurso contencioso administrativo interpuesto por la representación procesal de (...) contra Real Decreto 1720/2007, de 21 de diciembre, que realizamos en sentencia de 15 de julio de 2010, al artículo 10.2.b) del Real Decreto de mención, que anulamos por disconforme a derecho, sin hacer especial condena en costas».

28 En dichos apartados se trae a colación «la importancia de los derechos que los arts. 7 y 8 de la Carta de los Derechos Fundamentales de la UE confieren al interesado» — esto es, «respeto de la vida privada y 
la perspectiva del sistema de fuentes, el TJUE reafirmaba el principio de efecto directo del Derecho de la UE (apartado 52$)^{29}$.

En esta misma línea, por lo que se refiere a la AN, fue su Sala de lo Contencioso-Administrativo la que formuló la cuestión prejudicial que dio lugar al famoso caso Google Spain, SL (STJUE de 13 de mayo de 2014, asunto C-131/12) y a la consagración del denominado «derecho al olvido» (recogido en el art. 17 del reciente Reglamento General de Protección de Datos de la $U E^{31}$ bajo la denominación oficial de «derecho de supresión»), que ha sido objeto de gran atención doctrinal ${ }^{32}$.

Por su lado, aunque el TC se haya mostrado durante largo tiempo reacio a la utilización del mecanismo de las cuestiones prejudiciales ante el TJUE, sí cuenta con apuntes reveladores de una actitud claramente abierta a la asunción de la jurisprudencia comunitaria europea, llegando a subrayar que esa complementariedad viene impuesta por nuestro ordenamiento constitucional. En concreto, la STC 10/2005, de 20 de enero, suscita un claro paralelismo de estándares; de tal modo que, en caso de no haber existido la previa decisión prejudicial a la que el TC se refiere, él mismo podría haberla planteado antes de resolver las cuestiones de inconstitucionalidad de referencia ${ }^{33}$.

familiar» y «protección de los datos de carácter personal», respectivamente- y la jurisprudencia previa en la materia del propio TJUE.

29 Afirma el TJUE en ese apartado 52: «Resulta obligado hacer constar que el artículo 7, letra f), de la Directiva 95/46 es una disposición suficientemente precisa para poder ser invocada por un particular y aplicada por los órganos jurisdiccionales nacionales. Además, si bien no puede negarse que la Directiva 95/46 confiere a los Estados miembros un margen de apreciación más o menos grande para la aplicación de algunas de sus disposiciones, el citado artículo 7, letra f), enuncia, por su parte, una obligación incondicional».

30 La petición de decisión prejudicial versaba sobre la interpretación de diversos preceptos de la Directiva 95/46/CE del Parlamento Europeo y del Consejo, de 24 de octubre de 1995, relativa a la protección de las personas físicas en lo que respecta al tratamiento de datos personales y a la libre circulación de estos datos, y del art. 8 de la Carta de los Derechos Fundamentales de la UE. Dicha petición se presentó en el marco de un litigio entre Google Spain, S.L. y Google Inc., por un lado, y la Agencia Española de Protección de Datos y el Sr. Costeja González, por otro, en relación con una resolución de dicha Agencia por la que se estimó la reclamación del Sr. Costeja González contra ambas sociedades y se ordenaba a Google Inc. que adoptara las medidas necesarias para retirar los datos personales del Sr. Costeja González de su índice e imposibilitara el acceso futuro a los mismos.

31 Reglamento (UE) 2016/679 del Parlamento Europeo y del Consejo de 27 de abril de 2016, relativo a la protección de las personas físicas en lo que respecta al tratamiento de datos personales y a la libre circulación de estos datos y por el que se deroga la Directiva 95/46/CE.

32 Entre otros, A. Azurmendi, «Por un derecho al olvido para los europeos: aportaciones jurisprudenciales de la Sentencia del Tribunal de Justicia Europeo del caso Google Spain y su recepción por la Sentencia de la Audiencia Nacional Española de 29 de diciembre de 2014», Revista de Derecho Político, n. ${ }^{\circ}$ 92, 2015, pp. 273-310; A. Borx Palop, «El equilibro entre los derechos del artículo 18 de la Constitución, el «derecho al olvido» y las libertades informativas tras la sentencia Google», Revista General de Derecho Administrativo, n. ${ }^{\circ} 38,2015$, pp. 1-40; J. M. MArtínez OTERo, «El derecho al olvido en Internet: debates cerrados y cuestiones abiertas tras la STJUE Google vs AEPD y Mario Costeja», Revista de Derecho Político, n. ${ }^{\circ}$ 93, 2015, pp. 103-142; y, más ampliamente, la monografía de A. RAllo Lombarte, El derecho al olvido en Internet. Google versus España, Madrid, Centro de Estudios Políticos y Constitucionales, 2014.

33 Mediante la STC 10/2005 se resuelven las cuestiones de inconstitucionalidad 660-2000 y otras veintisiete (acumuladas) planteadas por la Sala de lo Contencioso-Administrativo del Tribunal Superior de Justicia 
Sea como fuere, la normal complementariedad de los estándares europeos y nacionales debe concebirse como la consecuencia natural de la vigencia de los principios de la primacía y el efecto directo del Derecho de la UE, que no sólo no es objeto de controversia, sino que ha sido enfatizada por la jurisprudencia constitucional española citando la doctrina al efecto del TJUE (STC 79/1992, de 28 de mayo, FJ 3). Por tanto, no conviene ahora detenerse en el alcance y proyección de dichos principios a tenor de la base habilitante del art. $93 \mathrm{CE}$, sobre lo que nuestra Jurisdicción Constitucional ya se ha pronunciado en diversas ocasiones ${ }^{34}$, acudiendo — como se acaba de señalar- a la cita clásica de la jurisprudencia comunitaria europea ${ }^{35}$.

Lo que, en cambio, es susceptible de dificultar la aplicación práctica de dichos principios del Derecho comunitario europeo radica en la propia complejidad del sistema constitucional de distribución competencial, que habrá de resolverse por el TC determinando a quién corresponderá (si al Estado o a la Comunidad o Comunidades Autónomas de que se trate) el título para dar cumplimiento o ejecución a las obligaciones comunitarias europeas ${ }^{36}$.

de Cataluña sobre el artículo 9.7 del Decreto 3313/1966, de 29 de diciembre, por el que se aprueba el texto refundido de la Ley del impuesto sobre actividades y beneficios comerciales e industriales. En el FJ 6 se argumenta que «la conclusión constitucional viene avalada también desde el Derecho comunitario, al que nuestro Ordenamiento debe permanecer abierto ex art. 93 CE desde la integración de España en las entonces Comunidades Europeas, en 1986. Y a este respecto puede traerse a colación aquí, por ejemplo, la Sentencia del Tribunal de Justicia de las Comunidades Europeas, de 15 de marzo de 1994, asunto C-387/92, que consideró contrarias al Derecho comunitario por ser ayudas de Estado aquellas exenciones fiscales a favor de entidades públicas o privadas que las coloquen «en una situación más favorable que a otros contribuyentes», y ello en una cuestión prejudicial que, de manera semejante en parte a lo aquí suscitado, versaba precisamente sobre legislación española (la Ley 13/1971), que establecía exenciones fiscales en favor de entidades públicas de crédito».

34 En efecto, nuestra jurisprudencia constitucional «ha venido reconociendo pacíficamente la primacía del Derecho comunitario europeo sobre el interno en el ámbito de las 'competencias derivadas de la Constitución', cuyo ejercicio España ha atribuido a las instituciones comunitarias con fundamento ... en el art. 93 CE» (por todas, Declaración 1/2004, de 13 de diciembre, FJ 4; o SSTC 145/2012, de 2 de julio, FJ 5, y 61/2013, de 14 de marzo, FJ 5).

35 Por todas, véase la STC 100/2012, de 28 de mayo, en cuyo FJ 7 puede leerse: «Una vez prestado el consentimiento por el Estado español, (...) aquella operación de cesión comporta «una determinada limitación o constricción, a ciertos efectos, de atribuciones y competencias de los poderes públicos españoles (limitación de 'derechos soberanos', en expresión del Tribunal de Justicia de las Comunidades, caso Costa/Enel, Sentencia de 15 de julio de 1964)» (DTC 1/1992, de 1 de julio, FJ 4) (...). Así, desde la incorporación de España a las Comunidades Europeas «se integró en el Ordenamiento español un sistema normativo autónomo, dotado de un régimen de aplicabilidad específico, basado en el principio de prevalencia de sus disposiciones propias frente a cualesquiera del orden interno con las que pudieran entrar en contradicción» (DTC 1/2004, de 13 de diciembre, FJ 4)».

36 A tal efecto, aunque «en los procesos constitucionales el Derecho comunitario no es, per se, canon o parámetro directo de contraste y examen de los actos y disposiciones de los poderes públicos», «ello no supone, no obstante, que este Tribunal no pueda tomar en consideración la normativa comunitaria, ya sea para concluir que la controvertida es una cuestión que cae dentro de la esfera del Derecho comunitario, y no en la del reparto interno de competencias, objeto del conflicto constitucional (STC 236/1991, de 12 de diciembre, FJ 10), ya sea para aplicar correctamente el esquema interno de distribución de competencias (STC 128/1999, FJ 9), mediante una más precisa determinación del título competencial en disputa, que ha de realizarse atendiendo al carácter de las normas objeto de la controversia competencial (STC 13/1998, de 22 de enero, FJ 4). 


\section{Sombras: Polémica sobre el alcance de la duda interpretativa y controversia sobre los niveles de protección de derechos y libertades}

La polémica sobre diversos cánones interpretativos y niveles de protección se suscitó de manera nítida con motivo de la STC 184/1990, de 15 de noviembre, en cuyo FJ 5 se trae a colación «la Sentencia del Tribunal de Justicia de la Comunidad Europea, de 17 de abril de 1986» para concluir que la asimilación a «cónyuge» que se opera en esa jurisprudencia comunitaria no sería trasladable a la situación sometida en sede jurisdiccional constitucional referente al requisito del vínculo matrimonial para el acceso a la pensión de viudedad ${ }^{37}$. Al contrario, en otros pronunciamientos, sin haber planteado tampoco la cuestión prejudicial, el TC parece haberse acercado más al parámetro interpretativo del TJUE (por ejemplo, STC 41/2013, de 14 de febrero ${ }^{38}$ ), e incluso al del TEDH y de otros tribunales supremos de países europeos (por ejemplo, STC $39 / 2002$, de 14 de febrero ${ }^{39}$ ), en el escenario del conocido como «diálogo judicial» ${ }^{40}$.

En la misma línea, ha habido ámbitos en los que el alto grado de sintonía entre el canon de constitucionalidad y el canon comunitario europeo ha conjurado cualquier riesgo de duda y, en consecuencia, de divergencia interpretativa, por lo que el TC no ha tenido reparo en alinearse con naturalidad con la jurisprudencia del TJUE. Así ha sucedido señaladamente en materia de lucha contra la posible discriminación indirecta por razón de sexo en perjuicio de la mujer en el terreno laboral y de la seguridad social. Buen exponente de ello lo ofrece, entre

Finalmente, este Tribunal distingue con nitidez entre la ejecución, en sí misma, y la garantía de la ejecución de las obligaciones iuscomunitarias» (STC 45/2001, de 15 de febrero, FJ 6).

37 En este caso, la STC 184/1990 sí cuenta con dos votos particulares, uno concurrente de V. Gimeno Sendra y otro discrepante de L. López Guerra.

38 La STC 41/2013 (especialmente, FJ 2) tiene su origen en la cuestión de inconstitucionalidad 8970 2008 planteada por el Juzgado de lo Social n. ${ }^{\circ} 33$ de Barcelona respecto de la disposición adicional tercera de la Ley 40/2007, de 4 de diciembre, de medidas en materia de Seguridad Social. Se concluye la nulidad del precepto legal impugnado, que supeditaba el disfrute del derecho a la pensión de viudedad que en él se establece a que el causante y el beneficiario hubieran tenido hijos comunes.

39 Cuestión de inconstitucionalidad 1724/95. Planteada por un Juzgado de Primera Instancia de Reus respecto del art. 9.2 del Código Civil, redactado por el Decreto 1836/1974, de 31 de mayo. En el FJ 5 se razona: «Este Tribunal, partiendo de la Constitución y de los textos comunitarios e internacionales sobre la igualdad, ha reaccionado siempre frente a toda norma o acto aplicativo que supusiese la discriminación de la mujer, alineándose así tanto con la doctrina del TEDH (Sentencia de 22 de febrero de 1994, caso Burghartz, en relación con la determinación del apellido familiar) como con la del Tribunal de Justicia de las Comunidades Europeas y otros Tribunales Constitucionales. En este mismo sentido, la Sentencia de 22 de febrero de 1983 del Tribunal Constitucional Federal Alemán, con relación a un supuesto que guarda esencial identidad al que es objeto de nuestro estudio, (...) Con idéntica orientación sentido la Corte Constitucional italiana sostuvo en su Sentencia de 26 de febrero de 1987 (...)».

40 Son numerosas las contribuciones doctrinales producidas en dicho ámbito en los últimos años; sirvan a título de ejemplo las contenidas en la obra de E. Ferrer Mac-Gregor, y A. Herrera García (Coords.), Diálogo Jurisprudencial en Derechos Humanos. Entre Tribunales Constitucionales y Cortes Internacionales, Tirant lo Blanch, Valencia, 2013. 
otras, la STC 253/2004, de 22 de diciembre ${ }^{41}$, cuyo FJ 7 cita un amplio elenco de pronunciamientos del Tribunal de Luxemburgo ${ }^{42}$.

Pero, sobre todo, la STC 61/2013, de 14 de marzo, resuelve un supuesto básicamente análogo ${ }^{43}$ no sólo al sustanciado en esa STC 253/2004 sino al resuelto previamente por la STJUE Elbal Moreno de 22 de noviembre de 2012 (asunto C-385/11), en el que se basa el TC con carácter explícito mostrando así que la doble prejudicialidad (constitucional y europea) no ha sido obstáculo para hacer valer las sinergias ${ }^{44}$.

Más polémicos se presentan, en cambio, otros pronunciamientos del TC que, pese a citar profusamente jurisprudencia del TJUE, no contemplan exactamente el supuesto litigioso aunque sí es objeto de controversia la misma disposición nacional, por lo que podrían surgir contenciosos paralelos (con potenciales soluciones divergentes) entre ambas jurisdicciones, la constitucional y la comunitaria,

41 Cuestión de inconstitucionalidad 2045/1998. Planteada por el Juzgado de lo Social n. ${ }^{\circ} 1$ de Pontevedra respecto del párrafo segundo del art. 12.4 de la Ley del estatuto de los trabajadores, en la versión del texto refundido de 1995. Se concluye la inconstitucionalidad de la norma cuestionada por vulneración de los derechos a la igualdad en la ley y a no sufrir discriminación por razón de sexo, a consecuencia de la determinación de los períodos de cotización de las prestaciones de Seguridad Social computando exclusivamente las horas trabajadas, en perjuicio de las trabajadoras a tiempo parcial.

42 En dicho FJ 7 puede leerse: «El concepto de la discriminación indirecta por razón de sexo ha sido elaborado por la jurisprudencia del Tribunal de Justicia de las Comunidades Europeas, precisamente con ocasión del enjuiciamiento de determinados supuestos de trabajo a tiempo parcial a la luz de la prohibición de discriminación por razón de sexo del art. 119 del Tratado de la Comunidad Económica Europea (actual art. 141 del Tratado de la Comunidad Europea) y las Directivas comunitarias de desarrollo. Puede resumirse en una fórmula reiterada por el Tribunal de Justicia de las Comunidades Europeas en múltiples de sus fallos (entre otras muchas, SSTJCE de 7 de febrero de 1991, asunto Nimz; de 4 de junio de 1992, asunto Bötel; o de 9 de febrero de 1999, asunto Seymour-Smith y Laura Pérez). (...) (STJCE de 14 de diciembre de 1995, asunto Megner y Schffel) (...) (STJCE de 14 de diciembre de 1995, asunto Nolte). Esta jurisprudencia del Tribunal de Justicia de las Comunidades Europeas sobre la discriminación indirecta por razón de sexo ha sido acogida por la doctrina del Tribunal Constitucional (...) (Sentencias del Tribunal de Justicia de las Comunidades Europeas, asuntos Bilka Kaufhaus, de 13 de mayo de 1986, o Kowalska, de 27 de junio de 1990, entre otros). (...) Y, en segundo lugar, se requiere que los poderes públicos no puedan probar que la norma que dispensa una diferencia de trato responde a una medida de política social, justificada por razones objetivas y ajena a toda discriminación por razón de sexo (por todas, SSTJCE de 14 de diciembre de 1995, asunto The Queen v. Secretary of State for Health; de 20 de marzo de 2003, asunto Jorgensen, y de 11 de septiembre de 2003, asunto Steinicke)».

43 Cuestión de inconstitucionalidad 5862-2003. Planteada por la Sala de lo Social del Tribunal Superior de Justicia de Galicia en relación con la disposición adicional séptima del texto refundido de la Ley General de la Seguridad Social, aprobado por el Real Decreto Legislativo 1/1994, de 20 de junio.

44 En el FJ 5 se argumenta: «Destacado ya el elemento clave de la decisión en la doble proyección de la duda de constitucionalidad planteada respecto al art. $14 \mathrm{CE}$, otro presupuesto adicional a tener en cuenta en nuestra resolución es el valor que debemos conceder a la Sentencia del Tribunal de Justicia de la Unión Europea de 22 de noviembre de 2012, asunto Elbal Moreno, dictada en relación con la prohibición de discriminación indirecta por razón de sexo derivada del art. 4 de la Directiva 79/7/CEE del Consejo — sobre aplicación progresiva del principio de igualdad de trato entre hombres y mujeres en materia de seguridad social一, y mediante la que el Tribunal de Justicia de la Unión Europea resuelve una petición de decisión prejudicial planteada por el Juzgado de lo Social n. 33 de Barcelona, mediante Auto de 4 de julio de 2011, relativa precisamente a la misma previsión normativa que ahora es objeto de la presente cuestión de inconstitucionalidad, esto es, la regla segunda del apartado 1 de la disposición adicional séptima LGSS». 
pareciendo entonces preferible que se activara el mecanismo de colaboración prejudicial. Como muestra de esa polémica cabe aludir a la STC 75/2011, de 29 de mayo $^{45}$, en cuyo FJ 7 figura una lista de cuatro sentencias del TJUE ${ }^{46}$.

Anteriormente, la duda interpretativa ya se había puesto de manifiesto de modo visible en otros asuntos en los que el TC podía haber planteado la cuestión prejudicial ante el TJUE. Así lo ilustra la STC 225/1993, de 8 de julio ${ }^{47}$, que cuenta con un voto particular discrepante suscrito por cuatro magistrados constitucionales en donde la disidencia se apoya precisamente en la jurisprudencia comunitaria: «El Tribunal de Justicia de la Comunidad Europea, que precisamente tiene encomendada la tarea de velar por la unidad del mercado europeo, ha reiterado en múltiples ocasiones que la diversidad de horarios comerciales en modo alguno conculca o pone en peligro esa unidad».

En este sentido, conviene apuntar que otro campo que presenta amplio riesgo de divergencia de enfoques por concurrencia de canon constitucional y de estándar europeo viene abonado por el alcance de las obligaciones tributarias (por ejemplo, SSTC 176/2011, de 8 de noviembre, FJ 5 58, 210/2012, de 14 de noviembre, FJ $9^{49}$, o 121/2016, de 23 de junio, FJ $5^{50}$ ), por lo que pese a la abundante jurisprudencia comunitaria en dicha materia (citada en dichas sentencias constitucionales) no cabe descartar que en el futuro puedan surgir al TC dudas interpretativas fundamentales susceptibles de ser planteadas ante el TJUE.

45 Cuestión de inconstitucionalidad 3515-2005. Planteada por el Juzgado de lo Social n. ${ }^{\circ} 1$ de Lleida en relación con el artículo 48.4 del texto refundido de la Ley del estatuto de los trabajadores, en la redacción dada por el artículo 5 de la Ley 39/1999, de 5 de noviembre. En el fallo se confirma la validez constitucional del precepto legal que impide la cesión al padre del disfrute del permiso de maternidad cuando la madre no sea trabajadora por cuenta ajena.

46 Se citan, concretamente, las SSTJUE de 12 de julio de 1984, caso Hofmann; de 30 de abril de 1998 , caso Thibault; de 27 de octubre de 1998, caso Boyle y otros; de 18 de marzo de 2004, caso Merino Gómez; y de 30 de septiembre de 2010, caso Roca Álvarez. En idéntico sentido, véase la STC 152/2011, de 29 de septiembre (FFJJ 3 y 4), con origen en la cuestión de inconstitucionalidad 648-2006 planteada por el Juzgado de lo Contencioso-Administrativo n. ${ }^{\circ} 1$ de Vigo en relación con el artículo 70.4 de la Ley del Parlamento de Galicia 4/1988, de 26 de mayo, de la función pública de Galicia.

47 Recursos de inconstitucionalidad 418/1987 y 421/1987 y cuestiones de inconstitucionalidad 1.902/1991 y 1.904/1991 (acumulados). Promovido, el primero, por 57 Diputados contra los arts. 3, 4, 9, 13.3, 17 y 43.2 a) de la Ley de la Generalidad Valenciana 8/1986, de 29 de diciembre, de Ordenación del Comercio y Superficies Comerciales; el segundo, por el Gobierno de la Nación contra el art. 9 de dicha Ley; y las cuestiones planteadas, ambas, en relación con el art. 9 de la mencionada Ley.

48 Recurso de inconstitucionalidad 1827-2000. Interpuesto por 60 Diputados del Grupo Parlamentario Socialista en el Congreso en relación con diversos preceptos de la Ley 55/1999, de 29 de diciembre, de medidas fiscales, administrativas y del orden social.

49 Recurso de inconstitucionalidad 1894-2002. Interpuesto por el Presidente del Gobierno en relación con la Ley de la Asamblea de Extremadura 14/2001, reguladora del impuesto sobre depósitos de las entidades de crédito.

50 Cuestión de inconstitucionalidad 6244-2014. Planteada por la Sala de lo Contencioso-Administrativo del TS en relación con la disposición adicional trigésima primera de la Ley 35/2006, de 28 de noviembre, del impuesto sobre la renta de las personas físicas y de modificación parcial de las Leyes de los impuestos sobre sociedades, sobre la renta de no residentes y sobre el patrimonio, incorporada por la disposición final cuadragésima novena, apartado primero, de la Ley 2/2011, de 4 de marzo, de economía sostenible. 
Finalmente, en conexión con la polémica sobre el alcance de las dudas acerca de la interpretación sistemática del ordenamiento jurídico, resulta insoslayable concluir el presente epígrafe aludiendo a la controversia sobre los niveles de protección de derechos y libertades generada a cuenta del conocido «caso Melloni». Como es sabido, tiene su origen en la primera cuestión prejudicial planteada por el TC español (mediante el Auto 86/2011, de 9 de junio), que tuvo su respuesta mediante la STJUE de 26 de febrero de 2013 (asunto C-399/11, Melloni), asumida mediante STC 26/2014, de 13 de febrero. Al margen de los votos particulares que acompañan a dicha sentencia constitucional y de la discusión doctrinal específica suscitada en España - la cual se inserta en el marco de un debate más amplio sobre la tutela multinivel de derechos ${ }^{51}$ en la doctrina constitucionalista italiana se han ofrecido elementos de interés desde la perspectiva del principio favor libertatis a la luz de los arts. 52.3 y 53 de la Carta de los Derechos Fundamentales de la UE y, correlativamente, de la teoría de los «contra-límites» ${ }^{52}$.

\section{LA EVOLUCIÓN DE LA NORMATIVA NACIONAL PROPICIADA POR LA JURISPRUDENCIA DEL TJUE}

\section{La normativa estatal}

Con carácter preliminar, debe recordarse que la eventual ejecución de las sentencias del TJUE por parte de las autoridades estatales, como específica ejecución del más amplio Derecho de la UE, ha de quedar delimitada con respecto a la competencia estatal en materia de relaciones internacionales (art 149.1.3. ${ }^{a} \mathrm{CE}$, en conexión con art. $93 \mathrm{CE}$ ), que comprende en su núcleo esencial el «treaty making power», la representación exterior y la responsabilidad internacional (STC 153/1989, de 5 de octubre).

Así pues, una cosa es la ejecución propiamente dicha (que, conviene avanzar ya, corresponderá a las autoridades estatales o a las autonómicas en función de la distribución constitucional interna de competencias) y otra bien diversa (en estrecha conexión con la responsabilidad internacional del Estado) la plena garantía del cumplimiento y ejecución de las obligaciones internacionales «y, en particular ahora, del Derecho Comunitario que al Estado encomienda el art. $93 \mathrm{CE}$ », la cual «necesariamente ha de dotar al Gobierno de la Nación de los instrumentos necesarios para desempeñar esa función garantista» (STC 252/1988, de 20 de diciembre, FJ 2), articulándose la cláusula de responsabilidad por medio de una

51 Una síntesis de las claves de esa tutela en T. Freixes SANJú́n, «Els drets fonamentals en perspectiva multinivell. Reflexions entorn dels seus efectes», Revista catalana de dret públic, n. ${ }^{\circ}$ 50, 2015, pp. 32-41.

52 Sobre la teoría de los «contra-límites» en la doctrina italiana, M. CARTABIA, Principi inviolabili e integrazione europea, Giuffrè, Milano, 1995, pp. 95 y ss. 
serie de poderes que permitan al Estado llevar a la práctica los compromisos internacionales adoptados.

Ahora bien, semejante cláusula de responsabilidad estatal «tampoco puede tener una incidencia o proyección interna que venga a alterar la distribución de poderes entre el Estado y las Comunidades Autónomas operada por el bloque de la constitucionalidad. Y es que, aun cuando en el art. $93 \mathrm{CE}$ se localiza una clara manifestación del monopolio competencial del Estado en orden a la garantía del cumplimiento de los compromisos adquiridos frente a otros sujetos de Derecho internacional, ya que esa garantía de la ejecución —no, desde luego, la ejecución misma- sí puede integrarse en el contenido del art. 149.1.3 CE, ello no quiere decir que la previsión del art. 93 de la CE configure por sí sola un título competencial autónomo a favor del Estado, sino que, ineludiblemente, ha de serlo por conexión con las competencias exteriores del Estado» (STC 80/1993, de 8 de marzo, FJ 3).

En consecuencia, «los poderes de control y vigilancia que, para el aseguramiento de la ejecución, deban corresponder al Estado lo que no pueden es afectar a la competencia misma que constitucionalmente deban desarrollar y ejercitar las Comunidades Autónomas, desplazándola o sustituyéndola anticipadamente por el ejercicio de poderes que, en ese caso, no serán ya de control y vigilancia» (mismo FJ 3 de la STC 80/1993). Verdaderamente, ya con anterioridad a la adhesión de España a las Comunidades Europeas, nuestra jurisprudencia constitucional había sostenido con carácter más general que, en virtud de la competencia exclusiva en la materia de relaciones internacionales (art. 149.1.3. ${ }^{a} \mathrm{CE}$ ), la dimensión exterior de un asunto no puede servir para realizar una interpretación expansiva de la citada disposición que venga a subsumir en la competencia estatal toda medida dotada de una cierta incidencia exterior por remota que sea (STC 125/1984, de 20 de diciembre).

Con estas premisas, son numerosos los ejemplos de ejecución — diríamostransversal (sin cita de un pronunciamiento o pronunciamientos concretos) de la jurisprudencia del TJUE a través de la legislación estatal. Y ello lo encontramos tanto en normativa reciente (que guarda congruencia asimismo con los ámbitos competenciales más recientemente transferidos a la dinámica de la «integración» europea, como el espacio de libertad, seguridad y justicia) como en disposiciones adoptadas en los primeros años de nuestra andadura por la senda comunitaria (que incorpora elementos más clásicos y que son objetos de constante actualización normativa y jurisprudencial, como es el supuesto de la libre circulación de trabajadores y el acceso a la función pública, el caso de los recursos propios de la UE o incluso de la coherencia que han de presentar los tributos estales con relación a la disciplina de las libertades económicas en el mercado interior).

Un ejemplo en relación con la normativa reciente viene suministrado, entre otros, por la LO 10/2015, de 10 de septiembre, por la que se regula el acceso y publicidad de determinada información contenida en las sentencias dictadas en materia de fraude fiscal, en cuyo Preámbulo indica «la presente Ley pondera 
adecuadamente los derechos del condenado y del resto de participantes en el proceso a la intimidad y a la protección de sus datos de acuerdo con la jurisprudencia de nuestros Tribunales y del Tribunal de Justicia de la Unión Europea, pues el acceso se limita a los datos del condenado o del responsable civil y no del resto de sujetos y solo respecto de las sentencias firmes». En conexión con el citado espacio de libertad, seguridad y justicia, como es sabido, la llamada «crisis de los refugiados» ha puesto de manifiesto, entre otros elementos como el socavamiento de los valores europeos (entre ellos, la solidaridad), las insuficiencias del marco normativo y los aspectos deficitarios del «sistema europeo común de asilo». Buen botón de muestra es que la vigente Ley 12/2009, de 30 de octubre, reguladora del derecho de asilo y de la protección subsidiaria descarta la modificación parcial de la anterior Ley 5/1984, de 26 de marzo (que abroga o deroga totalmente), dado el calado de los cambios necesitados ${ }^{53}$, y que según su Preámbulo se cifran no sólo en «las necesidades derivadas de la incorporación del amplio elenco de actos normativos de la Unión Europea», sino asimismo en «reflejar de modo adecuado las nuevas interpretaciones y criterios surgidos en la doctrina internacional y en la jurisprudencia de órganos supranacionales como el Tribunal de Justicia de las Comunidades Europeas o el Tribunal Europeo de Derechos Humanos, con el objeto de mejorar las garantías de las personas solicitantes y beneficiarias de protección internacional».

Por otro lado, buenos ejemplos del bloque de normativa menos reciente, con fórmulas parecidas de referencia genérica a «la jurisprudencia del TJUE» en el Preámbulo o en la Exposición de Motivos, son la Ley 17/1993, de 23 de diciembre, sobre el acceso a determinados sectores de la función pública de los nacionales de los demás Estados miembros de la Comunidad Europea; la Ley 37/1992, de 28 de diciembre, del Impuesto sobre el Valor Añadido (IVA); o las sucesivas leyes de presupuestos generales (por ejemplo, la Ley 22/2013, de 23 de diciembre, de Presupuestos Generales del Estado para el año 2014) ${ }^{54}$. Por otra parte, en

53 Un análisis crítico de los aspectos más controvertidos puede verse en R. García MaHAmUT, y J. GalParsoro, Régimen jurídico del derecho de asilo en la Ley 12/1999, CEPC, Madrid, 2010. En todo caso, la legislación nacional se muestra por sí sola insuficiente para afrontar los acuciantes retos europeos y, más aún, globales, que nos acechan, habiéndose observado que ningún Estado miembro de la UE «puede resolver el problema en sus distintas caras poliédricas por sí solo ante avalanchas humanas desesperadas que arriesgan sus vidas en el mar para arribar a Europa, aunque sea por distintos motivos al de la huida por persecución. Grecia, Italia, España, ni ningún otro país con frontera exterior puede afrontar por sí mismo una crisis de tal magnitud: Ni para rescatar y salvar las vidas en el mar, ni para dar protección internacional a las personas que huyen de persecuciones y guerras, ni para abordar los fenómenos migratorios, ni para atajar y cooperar con terceros Estados, ni para nada de nada»: R. GARcía MAнAмUT, «La ductilidad del derecho a la protección internacional (refugio y protección subsidiaria) ante las crisis humanitarias: un desafío para Europa y para el sistema europeo común de asilo», Teoría y Realidad Constitucional, n. ${ }^{\circ}$ 38, 2016, p. 237.

54 Otros ejemplos los encontramos en los Preámbulos o Exposiciones de motivos de Ley 47/1999, de 16 de diciembre, por la que se modifica el artículo 5 de la Ley 25/1971, de 19 de junio, de Protección a las Familias Numerosas; la ya derogada Ley 30/2007, de 30 de octubre, de Contratos del Sector Público (derogación mediante Real Decreto Legislativo 3/2011, de 14 de noviembre); la Ley 31/2007, de 30 de octubre, sobre procedimientos de contratación en los sectores del agua, la energía, los transportes y los servicios postales; la 
casos excepcionales, la alusión genérica a la jurisprudencia del TJUE no se contiene en el Preámbulo o la Exposición de Motivos, sino en el propio texto articulado: así, en el artículo 3 (Definiciones) de la Ley 17/2009, de 23 de noviembre, sobre el libre acceso a las actividades de servicios y su ejercicio, su apartado 11 establece que se entenderá por «razón imperiosa de interés general» la razón definida e interpretada por «la jurisprudencia del Tribunal de Justicia de las Comunidades Europeas».

En un plano intermedio, esto es, de combinación de referencias genéricas o transversales con pronunciamientos concretos y específicos, cabe aludir a la Ley 23/1994, de 6 de julio, por la que se modifica la Ley 37/1992, de 28 de diciembre, del Impuesto sobre el Valor Añadido5s. Todavía más significativo es el supuesto de la Ley 28/2014, de 27 de noviembre, por la que se modifican diversas leyes tributarias, y en cuyo Preámbulo se identifican hasta cuatro sentencias concretas del TJUE que son objeto de ejecución, así como una referencia genérica a su jurisprudencia.

Ciertamente, resulta de mayor interés la ejecución por vía legislativa de pronunciamientos precisos del TJUE ${ }^{56}$, que lamentablemente no son siempre citados con el debido rigor. Pongamos por caso, como ejemplo de dicho proceder, la Ley 50/1998, de 30 de diciembre, de Medidas Fiscales, Administrativas y del Orden Social (en cuya Exposición de motivos se dice que respecto del IVA «se adapta la normativa del impuesto a la sentencia del Tribunal de Justicia de las Comunidades Europeas de 5 de mayo de 1998»), o la Ley 14/2000, de 29 de diciembre, de Medidas fiscales, administrativas y del orden social (su Exposición

Ley 38/2007, de 16 de noviembre, por la que se modifica el texto refundido de la Ley del Estatuto de los Trabajadores; la Ley 2/2010, de 1 de marzo, por la que se trasponen determinadas Directivas en el ámbito de la imposición indirecta y se modifica la Ley del Impuesto sobre la Renta de no Residentes para adaptarla a la normativa comunitaria; la también derogada Ley 33/2010, de 5 de agosto, de modificación de la Ley 48/2003, de 26 de noviembre, de régimen económico y de prestación de servicios en los puertos de interés general; la Ley 13/2011, de 27 de mayo, de regulación del juego; la Ley 20/2013, de 9 de diciembre, de garantía de la unidad de mercado; o la Ley 21/2013, de 9 de diciembre, de evaluación ambiental.

55 En su Exposición de motivos se justifica dicha modificación a tenor de «los nuevos criterios establecidos por el Tribunal de Justicia de las Comunidades Europeas en la interpretación de dicha normativa y el objetivo permanente de perfeccionar la adaptación de nuestra legislación a la comunitaria», así como de «la sentencia del Tribunal de Justicia de las Comunidades Europeas, de 27 de octubre de 1993, [que] aclara los criterios de determinación de la base imponible». Otro ejemplo similar lo ofrece la Ley 45/1999, de 29 de noviembre, sobre el desplazamiento de trabajadores en el marco de una prestación de servicios transnacional o, con parecida técnica, la Ley 6/2001, de 8 de mayo, de modificación del Real Decreto legislativo 1302/1986, de 28 de junio, de evaluación de impacto ambiental (disposición derogada por el Real Decreto Legislativo $1 / 2008$, de 11 de enero).

56 Uno de los ejemplos tempranos de ejecución normativa de pronunciamiento concreto del TJUE tras nuestra adhesión a las Comunidades Europeas a partir del 1 de enero de 1986 viene constituido por la Ley 33/1988, de 11 de noviembre, sobre prelación de créditos por exacciones en favor de la Comunidad Europea del Carbón y del Acero (Preámbulo). Más recientemente, la Ley 3/2006, de 29 de marzo, de modificación de la Ley 37/1992, de 28 de diciembre, del Impuesto sobre el Valor Añadido (Exposición de motivos); o en la Ley 20/2015, de 14 de julio, de ordenación, supervisión y solvencia de las entidades aseguradoras y reaseguradoras (Preámbulo). 
de motivos señala, todavía más vagamente, que las disposiciones tributarias contenidas en el Título vienen exigidas «por imperativo legal», «como consecuencia de la reciente sentencia del Tribunal de Justicia de las Comunidades Europeas»). Efectivamente, aunque sea de sencilla identificación la sentencia de referencia a tenor de la temática abordada, es sabido que la fecha (sin precisar el asunto y/o el nombre del caso) resulta tanto más insuficiente cuanto que diversos pronunciamientos pueden figurar datados en el mismo día ${ }^{57}$.

Con mayor rigor y corrección, la Ley 13/1998, de 4 de mayo, de Ordenación del Mercado de Tabacos y Normativa Tributaria señalaba en su Exposición de motivos que «la nueva normativa mantiene, en cambio, siguiendo la jurisprudencia comunitaria y su reciente sentencia del Tribunal de Justicia de las Comunidades Europeas de 14 de diciembre de 1995 (asunto C-387/93 «Caso Banchero»), el monopolio del comercio al por menor de labores de tabaco a favor del Estado a través de la Red de Expendedurías de Tabaco y Timbre». Es más, a la luz de ese mismo ejemplo, reviste gran interés que la Ley 14/2013, de 27 de septiembre, de apoyo a los emprendedores y su internacionalización, proceda a modificar incluso la Exposición de motivos de la Ley 13/1998 para consignar explícitamente que ello responde a la ejecución de una nueva y concreta sentencia del TJUE ${ }^{58}$.

De cualquier forma, como cuando hemos aludido a la referencia genérica o transversal, también se concreta excepcionalmente la ejecución de una sentencia del TJUE no sólo en el Preámbulo y en el contenido del texto articulado, sino incluso en la rúbrica de la disposición correspondiente ${ }^{59}$. Esta evolución positiva, aunque no tan rigurosa (pues se cita la fecha, pero no el asunto ni la denominación del caso), se comprueba igualmente en la Ley 15/2014, de 16 de septiembre, de racionalización del Sector Público y otras medidas de reforma administrativa, en cuyo Preámbulo se expresa que el legislador procede con urgencia para dar

57 Más ejemplos de esa ejecución específica de sentencias del TJUE, no concretadas con el rigor exigible, los aportan los Preámbulos o Exposiciones de Motivos de la Ley 29/1991, de 16 de diciembre, de adecuación de determinados conceptos impositivos a las Directivas y Reglamentos de las Comunidades Europeas; la Ley 3/2009, de 3 de abril, sobre modificaciones estructurales de las sociedades mercantiles; la Ley 1/2014, de 28 de febrero, para la protección de los trabajadores a tiempo parcial y otras medidas urgentes en el orden económico y social; o la Ley 38/2015, de 29 de septiembre, del sector ferroviario.

58 En particular, la Disposición final primera (Modificación de la Ley 13/1998, de 4 de mayo, de Ordenación del Mercado de Tabacos y Normativa Tributaria) establece: «La Ley 13/1998, de 4 de mayo, de Ordenación del Mercado de Tabacos y Normativa Tributaria se modifica en los siguientes términos: Uno. Se añade un penúltimo párrafo a la Exposición de motivos: "Esta Ley también consagra la doctrina del principio de la libertad de circulación dentro de la Unión Europea en materia de venta minorista por parte de los expendedores consagrada en este caso por la Sentencia del Tribunal de Justicia de la Unión Europea, de 26 de abril de 2012, dictada en el Asunto C-456/10, y por la Sentencia del Tribunal Supremo, de 8 de noviembre de 2012, dictada en el recurso contencioso-administrativo número 1/59/2007"».

59 Así lo ilustran el Preámbulo y la Disposición final tercera de la Ley 26/2014, de 27 de noviembre, por la que se modifican la Ley 35/2006, de 28 de noviembre, del Impuesto sobre la Renta de las Personas Físicas, el texto refundido de la Ley del Impuesto sobre la Renta de no Residentes, aprobado por el Real Decreto Legislativo 5/2004, de 5 de marzo, y otras normas tributarias». 
cumplimiento a una sentencia del TJUE. Subyace, claramente, la pretensión de evitar un procedimiento de infracción ${ }^{60}$, sin perjuicio del margen de apreciación del que goza la Comisión ${ }^{61}$.

Por otra parte la jurisprudencia constitucional ha avalado que la circunstancia de «extraordinaria y urgente necesidad» que habilita al Gobierno para el uso del Decreto-Ley según el art. 86 CE concurriría cuando medie perentoriedad en el cumplimiento de obligaciones comunitarias europeas, precisamente para evitar un procedimiento de infracción ante el TJUE. Así, en la STC 329/2005 de 15 de diciembre ${ }^{62}$, se argumenta que, «si bien es cierto, como alega la parte recurrente, que no se explicaron detalladamente en su momento las razones de la «extraordinaria y urgente necesidad», dicha justificación se deduce de «una valoración conjunta de todos aquellos factores que determinaron al Gobierno a dictar la disposición legal excepcional» (STC 137/2003, de 3 de julio, FJ 3), en este caso, la necesidad de modificar la Ley 17/1997 de acuerdo con las indicaciones que la Comisión Europea había dirigido al Gobierno español a fin de evitar un procedimiento de infracción ante el Tribunal de Luxemburgo por vulnerar dicha Ley el principio de libre circulación de bienes y servicios» (FJ 11). Esta jurisprudencia constitucional se ha consolidado en asuntos posteriores $^{63}$, de manera clara en la STC 1/2012, de 13 de enero ${ }^{64}$.

60 Otro ejemplo anterior en tal dirección viene constituido por la Ley 13/2006, de 26 de mayo, por la que se deroga el régimen de enajenación de participaciones públicas en determinadas empresas establecido por la Ley 5/1995, de 23 de marzo, y sus disposiciones de desarrollo y ejecución.

61 Tal como ha expuesto D. Sarmiento Ramírez-Escudero, El Derecho de la Unión Europea, Marcial Pons, Madrid, 2016, p. 387: «La abrumadora mayoría de los recursos por incumplimiento se tramitan a iniciativa de la Comisión, quien dispone de un amplio margen de apreciación a este respecto. La jurisprudencia ha declarado en reiteradas ocasiones que la negativa de la Comisión a iniciar los trámites del recurso contra un Estado, incluso a instancias de un denunciante, no constituye la infracción de un deber de actuación».

62 Recursos de inconstitucionalidad 1785/1997, 3000/1997 y 5246/1997 (acumulados). Promovidos por Diputados del grupo parlamentario socialista frente al Real Decreto-ley 1/1997, de 31 de enero; la Ley 17/1997, de 3 de mayo, y el Real Decreto-ley 16/1997, de 13 de septiembre, sobre el uso de normas para la transmisión de señales de televisión y medidas adicionales para la liberalización del sector.

63 En relación con esta cuestión, resulta interesante la lectura del Informe del Consejo de Estado sobre la inserción del Derecho europeo en el ordenamiento español, de 14 de febrero de 2008, pp. 208-209: «resulta pertinente advertir la necesidad de una esmerada conciliación entre la calidad de la norma, el control parlamentario y su aprobación en plazo, no percibiéndose a priori las ventajas de establecer un procedimiento legislativo específico (con plazos más breves) ni la utilidad de configurar un tipo normativo característico, cuya finalidad no fuera otra que abordar de forma conjunta las obligaciones de transposición que cada año correspondieran al Estado español (posibilidad ésta de escaso atractivo conceptual). Sea cual fuere la solución adoptada, lo que sí parece imprescindible es la consagración del carácter prioritario en la tramitación parlamentaria de todos los proyectos de ley que tienen por objeto incorporar disposiciones comunitarias y la introducción, quizá, de alguna previsión específica adicional, por ejemplo para reducir notablemente los plazos cuando el proyecto de ley tuviese por objeto dar cumplimiento a una sentencia del Tribunal de Justicia de las Comunidades Europeas que condenara a España o para impedir el decaimiento sin más, ante la convocatoria de elecciones generales, de un proyecto de ley de transposición (como, por ejemplo, sucedió en la IV Legislatura a propósito del proyecto de Ley de Contratos de las Administraciones Públicas)».

64 Recurso de inconstitucionalidad 71-2001. Interpuesto por el Consejo de Gobierno de la Comunidad Autónoma de Andalucía en relación con diversos preceptos del Real Decreto-ley 9/2000, de 6 de octubre, de modificación del Real Decreto Legislativo 1302/1986, de 28 de junio, de evaluación de impacto ambiental. 
No obstante, cabe matizar que en ocasiones no nos hallamos ante una ejecución que podríamos denominar «fuerte», es decir, que ponga en entredicho directamente a España, sino más bien ante una ejecución «débil» derivada de la interpretación efectuada por el TJUE y proyectada al conjunto de países miembros en aras de la igualdad y de la seguridad jurídica. En esa línea se inscribe la Ley 4/2008, de 23 de diciembre, por la que se suprime el gravamen del Impuesto sobre el Patrimonio, se generaliza el sistema de devolución mensual en el Impuesto sobre el Valor Añadido, y se introducen otras modificaciones en la normativa tributaria; en su Exposición de motivos se singulariza la adecuación «a la jurisprudencia comunitaria, básicamente, a la sentencia de 27 de noviembre de 2003, recaída en el Asunto C-497/01, Zita Modes Sarl», además de aludirse expresamente a la interpretación en la materia efectuada por «el mismo Tribunal de Justicia de las Comunidades Europeas (Auto de 16 de abril de 2008, recaído en el Asunto C-186/07)».

\section{La normativa autonómica}

A la luz de lo acabado de exponer, no cabe una interpretación expansiva del art. 149.1.3. ${ }^{a}$ CE que genere una «reordenación del propio orden constitucional de distribución de competencias entre el Estado y las Comunidades Autónomas» (entre otras, las SSTC 153/1989, de 5 de octubre, 54/1990, de 28 de marzo, 76/1991, de 11 de abril y 100/1991, de 13 mayo). Por lo tanto, con relación a la ejecución del Derecho de la UE (y de las concretas sentencias del TJUE $)^{65}$ son las reglas internas de delimitación competencial las que, en todo caso, han de fundamentar la respuesta a los conflictos de competencia surgidos entre el Estado y las Comunidades Autónomas (por ejemplo, STC 115/1991, de 23 de mayo).

Así lo ha observado el mismo TC, quien corrobora esa lectura «desde el propio Derecho Comunitario, en el que consolidada jurisprudencia del Tribunal de Justicia ha consagrado el llamado principio de autonomía institucional y procedimental, en virtud del cual, cuando las disposiciones de los Tratados o demás normas comunitarias reconocen poderes a los Estados miembros o les imponen obligaciones en orden a la aplicación del Derecho Comunitario, la cuestión de saber de qué forma el ejercicio de esos poderes y la ejecución de las obligaciones pueden ser confiadas por los Estados miembros a determinados órganos internos depende únicamente del sistema constitucional de cada Estado miembro» (STC 80/1993, de 8 de marzo, FJ 3).

65 En última instancia, la ejecución de las sentencias del TJUE no es sino una vertiente fundamental de la más amplia ejecución del Derecho de la UE, como ha analizado D. OrdóÑez Solís, La ejecución del Derecho Comunitario Europeo en España, Civitas, Madrid, 1994. 
Clarificadora al respecto es la STJUE Comisión c. España (asunto C-417/99) de 13 de septiembre de 2001, que vino a resolver un recurso por incumplimiento y que concluyó la infracción del Estado español por la omisión consistente en no designar a las autoridades competentes y a los organismos encargados de la aplicación de la Directiva 96/62/CE sobre evaluación y gestión de la calidad del aire ambiente, pues se observó que «tal como se desprende del cuadro que figura en el escrito de contestación, que ofrece una síntesis de las normas adoptadas por las Comunidades Autónomas para designar a las autoridades y a los organismos competentes en el ámbito cubierto por la Directiva 96/62, la mayoría de esas normas sólo fueron aprobadas o modificadas durante el segundo semestre del año 1999 , es decir, después de que expirase el plazo fijado en el dictamen motivado» (apartado 35) ${ }^{66}$.

Sin embargo, cuando a tenor de ese principio de autonomía, la ejecución de obligaciones comunitarias europeas cuya titularidad corresponde a una Comunidad Autónoma no es ejercida, la injerencia estatal (justamente en virtud del juego combinado de los arts. 93 y 149.1.3. ${ }^{a} \mathrm{CE}$ ) no quedará desprovista de efectos materiales hasta tanto se proceda al efectivo ejercicio en el plano regional; en otras palabras, la actuación material del Estado quedará provisionalmente avalada en congruencia con el principio de lealtad con esas obligaciones comunitarias, máxime cuando medie además una sentencia condenatoria para España del TJUE que debe ser consecuentemente ejecutada, como pone de manifiesto la STC $195 / 1998$, de 1 de octubre ${ }^{67}$ (especialmente, el FJ 5) y, en idéntico sentido, la STC 97/2002, de 25 de abrill $^{68}$.

De igual forma, esa autonomía institucional y procedimental no se ha traducido siempre en una potenciación de la autonomía política de las nacionalidades y regiones españolas en la fase descendente del Derecho comunitario europeo, puesto que la mencionada interpretación no expansiva del art. 149.1.3. ${ }^{a} \mathrm{CE}$ no ha sido obstáculo para que el TC avale otros títulos competenciales estatales tendentes a dar prioridad a la ejecución estatal. Uno de esos títulos es el relativo a la competencia estatal para propiciar la «igualdad básica» en todo el territorio nacional ex art. 149.1.1. ${ }^{\text {a }} \mathrm{CE}$, lo cual ha llevado a considerar constitucionalmente

66 Este razonamiento se apoya en la jurisprudencia del Tribunal de Luxemburgo según la cual «todo Estado miembro es libre para distribuir, como considere oportuno, las competencias internas y de ejecutar una Directiva por medio de disposiciones de las autoridades regionales o locales. Esta distribución de competencias, sin embargo, no puede dispensarle de la obligación de garantizar que las disposiciones de la Directiva sean fielmente reflejadas en el Derecho interno (véanse las sentencias de 14 de enero de 1988, caso Comisión contra Bélgica; y de 28 de febrero de 1991, caso Comisión contra Alemania)» (apartado 37).

67 Recurso de inconstitucionalidad 1705/1992. Promovido por el Consejo de Gobierno de la Diputación Regional de Cantabria en relación con el art. 21,3 de la Ley 4/1989, de Conservación de los Espacios Naturales y la Flora y la Fauna Silvestres, y los arts. 2 y 3 y el anexo de la Ley 6/1992 por la que se declara Reserva Natural de las Marismas de Santoña y Noja.

68 Recursos de inconstitucionalidad $3492 / 95$ y $3672 / 95$ (acumulados). Promovidos por el Gobierno y el Parlamento de la Comunidad Autónoma de las Illes Balears contra la Ley 26/1995, de 31 de julio, por la que se declara reserva natural las Salinas de Ibiza («Ses Salines»), las Islas des Freus y las Salinas de Formentera. 
legítimo el establecimiento de un Registro estatal de marcas y normes comerciales, apelándose incluso a la jurisprudencia comunitaria de la que se extraerían «elementos esenciales del 'sistema de competencia no falseado' (Sentencia de 17 de octubre de 1990, del Tribunal de Justicia de las Comunidades Europeas) sobre el que se asienta el mercado único nacional»(STC 103/1999, de 3 de junio $\left.^{69}\right)$. Y otro título que ha jugado un papel «centralizador» similar es la ordenación general de la economía ex art. $149.1 .13 .{ }^{a} \mathrm{CE}$, lo que ha conducido, entre otros supuestos, a desplazar la competencia autonómica (por ejemplo, STC 193/2013, de 21 de noviembre) ${ }^{70}$. Ambos títulos (artículo 149.1.1. ${ }^{a}$ y $13 .{ }^{a} \mathrm{CE}$ ) constituirían así competencias transversales u horizontales que justificarían la prevalencia estatal ${ }^{71}$.

\section{LA CONCRETA EJECUCIÓN DE SENTENCIAS DEL TJUE POR VÍA EJECUTIVA Y LEGISLATIVA}

\section{Luces: normal ejecución gubernamental e incontrovertida implementación legislativa}

Desde luego, la obligación de ejecución de las sentencias del TJUE por vía ejecutiva y administrativa en el ámbito doméstico no deriva únicamente del genérico respeto del sistema de fuentes y de lo dispuesto de manera más concreta en el art. 93 CE, sino asimismo del propio principio de responsabilidad de los poderes públicos establecido en el art. 9.3 CE ${ }^{72}$. Esta idea la recoge muy claramente la Ley 17/2011, de 5 de julio, de seguridad alimentaria y nutrición cuando señala en su Preámbulo que «se establece un principio de responsabilidad por la acción u omisión en el desempeño de las actividades de las administraciones en la materia, cuando de las mismas se derive un perjuicio económico para el país, fundamentalmente en nuestras relaciones con la Unión Europea. Así, si el Tribunal de Justicia de las Comunidades

69 Recursos de inconstitucionalidad 265/1989 y 266/1989 (acumulados). Promovidos, respectivamente, por el Gobierno Vasco y el Parlamento de Cataluña contra los arts. 15, 16, 17, 24, 27, 28 45 (apartado primero), 75, 81 /párrafo segundo) y 85 y la Disposición transitoria primera de la Ley 32/1988, de 10 de noviembre, de Marcas. Véase, especialmente, el FJ 5.

70 Recurso de inconstitucionalidad 5491-2012. Interpuesto por el Presidente del Gobierno en relación con el artículo 9.3 y 4 del Decreto-ley 1/2009, de 22 de diciembre, de ordenación de equipamientos comerciales de Cataluña, en la redacción dada por la Ley del Parlamento de Cataluña 9/2011, de 29 de diciembre, de promoción de la actividad económica de Cataluña. Véase asimismo la previa STC 26/2013, de 23 de enero.

71 T. De la Quadra-Salcedo Janini, «Delimitación de competencias y principio de prevalencia», P. Pérez Tremps (Coord.), La reforma del Tribunal Constitucional, Tirant lo Blanch, Valencia, 2007, p. 1025.

72 Por tanto, la inejecución de sentencias del TJUE comporta una clara conculcación de ese principio de responsabilidad, en su doble vertiente constitucional e internacional, como ha puesto de manifiesto J. M. SÁNChez Patrón, «La inejecución de sentencias del Tribunal de Justicia de la Unión Europea: la jurisprudencia en la materia a partir del caso español», V. E. Bou Franch, y M. Cervera Vallterra (Coords.), El Derecho de la Unión Europea: 20 años después de la adhesión de España, Tirant lo Blanch, Valencia, 2007, pp. 389-416. 
Europeas condenara a España al pago de una multa coercitiva por las irregularidades surgidas en la actuación de alguna administración en el campo de la seguridad alimentaria, el importe de la misma le sería detraído en el siguiente ejercicio presupuestario de las partidas que hubieran de serle transferidas desde la Administración General del Estado. Todo ello en el marco de un procedimiento que garantice la audiencia de la administración afectada».

Ahora bien, esa responsabilidad se ha previsto con carácter más general en la LO 2/2012, de 27 de abril, de Estabilidad Presupuestaria y Sostenibilidad Financiera, cuya disposición adicional segunda establece que las Administraciones Públicas y cualesquiera otras entidades integrantes del sector público que, en el ejercicio de sus competencias, incumplieran obligaciones derivadas de normas del Derecho de la Unión Europea, dando lugar a que el Reino de España sea sancionado por las instituciones asumirán, en la parte que les sea imputable, las responsabilidades que se devenguen de tal incumplimiento. Asimismo, dispone que corresponde al Consejo de Ministros declarar la responsabilidad por dicho incumplimiento y acordar, en su caso, la compensación o retención que corresponda.

En desarrollo de la citada disposición adicional segunda, y por habilitación expresa de su apartado 3, el Gobierno aprobó el Real Decreto 515/2013, de 5 de julio, por el que se regulan los criterios y el procedimiento para determinar y repercutir las responsabilidades por incumplimiento del Derecho de la Unión Europea, norma que, según se expone en su Preámbulo, «desarrolla un procedimiento general de determinación y repercusión de las responsabilidades derivadas de los incumplimientos del Derecho de la Unión Europea. La existencia del citado procedimiento general, supone una gran novedad en el ordenamiento jurídico español, ya que hasta la fecha sólo existían regulaciones dispersas y de carácter sectorial en determinadas materias, como son la gestión de fondos procedentes de la Unión Europea, los compromisos adquiridos en materia de estabilidad presupuestaria, en materia de aguas o los servicios del mercado interior».

Para la redacción del Real Decreto, como se recuerda asimismo en su Preámbulo, se tuvieron en cuenta las recomendaciones efectuadas por el Consejo de Estado en su Informe de 15 de diciembre de 2010 acerca de los mecanismos existentes en el ordenamiento español para garantizar el cumplimiento del Derecho de la Unión Europea y, en su caso, repercutir la responsabilidad a los sujetos incumplidores. De manera más precisa, en el art. 3.3.e) del Real Decreto $515 / 2013$ se singularizan entre los incumplimientos del Derecho de la UE la falta de ejecución o la ejecución incorrecta de sentencias del TJUE ${ }^{73}$, en la línea de lo que constituye el objeto del presente trabajo.

73 Según el citado art. 3.3 del Real Decreto 515/2013:

«Se entenderá que existe un incumplimiento cuando se realicen actuaciones u omisiones contrarias al Derecho de la Unión Europea y en particular, entre otros, en los siguientes supuestos:

a) Transposición tardía de directivas europeas al ordenamiento jurídico. b) Transposición incorrecta de directivas europeas al ordenamiento jurídico. c) Adecuación tardía o incorrecta de la normativa autonómica a 
En fin, en lo atinente a supuestos incontrovertidos de implementación legislativa, basta con remitirnos a los ejemplos de ejecución concreta expuestos en el apartado IV.

\section{Sombras: Polémica acerca del grado de ejecución y controversia sobre la suficiencia normativa}

La ya reseñada STC 193/2013, de 21 de noviembre (en la que se hizo prevalecer la competencia estatal sobre ordenación general de la economía ex art. 149.1.13. ${ }^{a} \mathrm{CE}$ en detrimento de la competencia autonómica exclusiva en materia de comercio interior) introdujo un elemento de gran interés en relación con el grado de ejecución de las sentencias del TJUE. En efecto, es interesante advertir que en el FJ 5 de la propia sentencia se recuerda el precedente de la condena impuesta por el TJUE al Estado español como consecuencia del incumplimiento atribuido a la Comunidad Autónoma de Cataluña en dicho ámbito.

Desde esta perspectiva, la ejecución de una sentencia condenatoria del TJUE afectante al ámbito autonómico no debe articularse de un modo fraudulento a través de una nueva normativa regional (de igual o incluso mayor rango) que intente sortear la infracción o el incumplimiento apreciados por la Justicia europea. En tal hipótesis, el asunto podría llegar otra vez al TJUE a través de un nuevo procedimiento de infracción iniciado por la Comisión o, incluso, por medio de un proceso de constitucionalidad en el que el parámetro europeo sirva materialmente de canon determinante para la Justicia constitucional. Semejante dinámica fraudulenta por parte de las autoridades públicas catalanas ha proseguido, lo que ha dado lugar a recientes pronunciamientos contundentes de nuestra Jurisdicción Constitucional como la STC 128/2016, de 26 de julio $^{74}$, que vuelve a deslegitimar (por contrariar los parámetros constitucionales y europeos), entre otras, las medidas autonómicas referentes a establecimientos comerciales ${ }^{75}$, que el Gobierno reprocha en su recurso de inconstitucionalidad por «poner de manifiesto la reiteración y contumacia en la infracción en la que se vuelve a incidir» [Antecedente 1.j)].

la legislación básica estatal dictada en cumplimiento del Derecho de la Unión Europea. d) Mantenimiento en vigor o aprobación de normas contrarias al Derecho de la Unión Europea. e) Falta de ejecución o ejecución incorrecta de sentencias, actos o decisiones dictados por las instituciones europeas».

74 Recurso de inconstitucionalidad 3493-2015. Interpuesto por el Presidente del Gobierno en relación con diversos preceptos de la Ley del Parlamento de Cataluña 3/2015, de 11 de marzo, de medidas fiscales, financieras y administrativas.

75 En el fallo de la STC 128/2016, se declara la nulidad de los preceptos legales autonómicos que confieren al servicio de meteorología de Cataluña una función de apoyo a la navegación aérea, regulan la implantación de establecimientos comerciales en los puertos de titularidad pública, el plan director de la Administración tributaria de Cataluña, el catálogo de infraestructuras estratégicas y el plan director de los sectores de energía, telecomunicaciones, sistemas de información y transporte ferroviario; y se establece una interpretación conforme de los preceptos relativos al inventario del patrimonio de las Administraciones públicas de Cataluña y de creación de la Agencia Catalana de Protección Social. 
En este ámbito, otro asunto interesante lo ofrece la Sentencia Comisión c. España de 9 de diciembre de 2004 (asunto C-79/03), que tiene su origen en el recurso por incumplimiento formulado por la Comisión y a resultas del cual el TJUE declaró que, al tolerar la práctica de la caza con liga en el territorio de la Comunitat Valenciana mediante el método conocido como «parany» (avalado por el Decreto valenciano 135/2000, de 12 de septiembre de 2000), España había incumplido las obligaciones que le incumbían en virtud de la Directiva 79/409/ CEE del Consejo, de 2 de abril de 1979, relativa a la conservación de las aves silvestres. Pues bien, tras dicha condena, el Parlamento regional valenciano adoptó una Ley tendente a convalidar el citado incumplimiento, lo que dio lugar a la STC 114/2013, de 9 de mayo ${ }^{76}$, mediante la que se declaró su inconstitucionalidad con el aval del previo pronunciamiento del TJUE (en particular, FJ 3).

Desde otro punto de vista, el concreto modo de proceder a la ejecución de un pronunciamiento del Tribunal de Luxemburgo ha adquirido una complejidad extraordinaria con motivo de la STJUE de 14 de septiembre de 2016 (caso Ana de Diego Porras y Ministerio de Defensa, asunto C-596/14) ${ }^{77}$, que tiene su origen en la cuestión prejudicial formulada por el TSJ de Madrid en el marco del litigio entre ambas partes relativo a la calificación de la relación laboral que les vincula y al abono de una indemnización como consecuencia de la extinción de dicha relación ${ }^{78}$. Ello ha generado todo un debate acerca de la equiparación de fijos e interinos y, como consecuencia de la problemática suscitada por la interpretación y la ejecución de dicho pronunciamiento, una compleja distinción entre las diversas categorías de contratos tanto en el sector público como en el privado. El debate ciertamente se ha acentuado en el escenario de la crisis económica y los desafíos que se presentan en el marco de la UE en materia de derechos y políticas sociales ${ }^{79}$.

76 Recurso de inconstitucionalidad 630-2010. Interpuesto por el Presidente del Gobierno en relación con el artículo 10 de la Ley de las Cortes Valencianas 13/2004, de 27 de diciembre, de caza de la Comunidad Valenciana, en la redacción dada al mismo por la Ley de las Cortes Valencianas 7/2009, de 22 de octubre, de reforma de los arts. 7 y 10 de la Ley 13/2004. Véase, en idéntico sentido, la STC 69/2013, de 14 de marzo (FJ 6), que tiene su origen en el recurso de inconstitucionalidad 2124-2008, interpuesto por el Consejo de Gobierno de la Junta de Castilla y León en relación con diversos preceptos de la Ley 42/2007, de 13 de diciembre, del patrimonio natural y la biodiversidad.

77 Desde la perspectiva del Derecho de la UE, léase sobre esta problemática J. M. SÁNCHEZ PATRÓN, «El procedimiento de ejecución de sentencias: la jurisprudencia del Tribunal de Justicia», Noticias de la Unión Europea, n. ${ }^{\circ} 264,2007$, pp. 25-31.

78 En el punto 2 del fallo puede leerse: «La cláusula 4 del Acuerdo marco sobre el trabajo de duración determinada, que figura en el anexo de la Directiva 1999/70, debe interpretarse en el sentido de que se opone a una normativa nacional, como la controvertida en el litigio principal, que deniega cualquier indemnización por finalización de contrato al trabajador con contrato de interinidad, mientras que permite la concesión de tal indemnización, en particular, a los trabajadores fijos comparables. El mero hecho de que este trabajador haya prestado sus servicios en virtud de un contrato de interinidad no puede constituir una razón objetiva que permita justificar la negativa a que dicho trabajador tenga derecho a la mencionada indemnización».

79 Un análisis reciente de esos desafíos en L. Jimena Quesada, Social Rights and Policies in the European Union: New Challenges in a Context of Economic Crisis, Tirant lo Blanch, Valencia, 2016. 
En cualquier caso, la controversia sobre el grado de ejecución se ha proyectado sobre el nivel de suficiencia de la norma tendente a dicha ejecución. Así, seguramente uno de los casos más mediáticos del impacto de la jurisprudencia del TJUE en el sistema constitucional español venga dado por la Sentencia $A z i z$ de 14 de marzo de 2013 (asunto C-415/11), pronunciada en el escenario de la crisis económica y de la desestabilización del sector bancario (impagos de hipotecas, desahucios, etc. $)^{80}$. Ese impacto intentó ser contrarrestado mediante una apremiante intervención legislativa que se plasmó sólo dos meses más tarde en la Ley $1 / 2013$, de 14 de mayo, de medidas para reforzar la protección a los deudores hipotecarios, reestructuración de deuda y alquiler social, en cuyo Preámbulo se cita explícitamente dicha Sentencia como causa directa de la acción normativa.

Dicho lo cual, el alcance limitado de la citada STJUE $A z i z$ vino a confirmarse con la STJUE Sánchez Morcillo de 17 de julio de 2014 (asunto C-169/14) ${ }^{81}$, para cuya ejecución concreta se dictó en menos de un año la Ley 9/2015, de 25 de mayo, de medidas urgentes en materia concursal ${ }^{82}$. El caso es que la correcta transposición en España de la Directiva 93/13/CEE del Consejo, de 5 de abril de 1993, sobre las cláusulas abusivas en los contratos celebrados con consumidores ha seguido planteando problemas derivados, en buena medida, de las sombras que proyecta el margen de apreciación judicial en cada caso concreto $^{83}$, como puso de manifiesto el

80 Resulta interesante, especialmente, el punto dispositivo primero del fallo: «La Directiva 93/13/ CEE del Consejo, de 5 de abril de 1993, sobre las cláusulas abusivas en los contratos celebrados con consumidores, debe interpretarse en el sentido de que se opone a una normativa de un Estado miembro, como la controvertida en el litigio principal, que, al mismo tiempo que no prevé, en el marco del procedimiento de ejecución hipotecaria, la posibilidad de formular motivos de oposición basados en el carácter abusivo de una cláusula contractual que constituye el fundamento del título ejecutivo, no permite que el juez que conozca del proceso declarativo, competente para apreciar el carácter abusivo de esa cláusula, adopte medidas cautelares, entre ellas, en particular, la suspensión del procedimiento de ejecución hipotecaria, cuando acordar tales medidas sea necesario para garantizar la plena eficacia de su decisión final».

81 En el fallo se dispone: «El artículo 7, apartado 1, de la Directiva 93/13/CEE del Consejo, de 5 de abril de 1993, sobre las cláusulas abusivas en los contratos celebrados con consumidores, en relación con el artículo 47 de la Carta de los Derechos Fundamentales de la Unión Europea, debe interpretase en el sentido de que se opone a un sistema de procedimientos de ejecución, como el controvertido en el litigio principal, que establece que el procedimiento de ejecución hipotecaria no podrá ser suspendido por el juez que conozca del proceso declarativo, juez que, en su resolución final, podrá acordar a lo sumo una indemnización que compense el perjuicio sufrido por el consumidor, en la medida en que éste, en su condición de deudor ejecutado, no puede recurrir en apelación contra la resolución mediante la que se desestime su oposición a la ejecución, mientras que el profesional, acreedor ejecutante, sí puede interponer recurso de apelación contra la resolución que acuerde el sobreseimiento de la ejecución o declare la inaplicación de una cláusula abusiva».

82 Se dice así en el Preámbulo: «La disposición final tercera modifica la Ley 1/2000, de 7 de enero, de Enjuiciamiento Civil, para adaptarla a la reciente sentencia del Tribunal de Justicia de la Unión Europea de 17 de julio de 2014. Con ello, el deudor hipotecario podrá interponer recurso de apelación contra el auto que desestime su oposición a la ejecución, si ésta se fundaba en la existencia de una cláusula contractual abusiva que constituya el fundamento de la ejecución o la cantidad exigible».

83 Indudablemente, esa discrecionalidad de la jurisdicción nacional debe leerse a la luz del margen de apreciación nacional que ofrecen las normas europeas, que a su vez no puede prescindir en muchas materias de la interpretación prevalente llevada a cabo tanto por las máximas instancias judiciales continentales (tanto el TJUE 
Preámbulo de la Ley 3/2014, de 27 de marzo, por la que se modifica el texto refundido de la Ley General para la Defensa de los Consumidores y Usuarios y otras leyes complementarias, aprobado por el Real Decreto Legislativo 1/2007, de 16 de noviembre, en donde se expresa que «la ley procede a dar cumplimiento a la sentencia de 14 de junio de 2012, en el asunto C-618 Banco Español de Crédito».

$\mathrm{Y}$ el final de este recorrido no dibuja un panorama muy tranquilizador pues, nuevamente, otra norma, concretamente la Ley 42/2015, de 5 de octubre, de reforma de la Ley 1/2000, de 7 de enero, de Enjuiciamiento Civil, viene a ejecutar sentencias concretas del TJUE que teóricamente ya habían sido objeto de ejecución mediante leyes previas. Lo cual pone obviamente de manifiesto el carácter imperfecto y deficitario de la ejecución de esos pronunciamientos del TJUE. Por otra parte, la Justicia comunitaria ha corregido mediante un pronunciamiento reciente — de gran eco mediático y alcance económico para la banca en Españala interpretación que venía efectuando el Tribunal Supremo limitando los efectos en el tiempo de la declaración de nulidad de las cláusulas abusivas en los préstamos hipotecarios: se trata de la STJUE Gutiérrez Naranjo y otros de 21 de diciembre de 2016 (asuntos acumulados C-154/15, C-307/15 y C-308/15) ${ }^{84}$.

En realidad, al margen de la implicación y conexión concretas con el derecho a la vivienda, la experiencia legislativa española había mostrado anteriormente sus insuficiencias en el terreno de la garantía de los derechos de consumidores y usuarios, por lo que el TJUE ya había condenado a España. Sirva de ejemplo la Ley 44/2006, de 29 de diciembre, de mejora de la protección de los consumidores y usuarios, cuya Exposición de motivos da cuenta de esas condenas y de los avatares legislativos en España como consecuencia de ello.

En cualquier caso, la defensa de los consumidores y usuarios adquiere perfiles crecientemente complejos como consecuencia del desarrollo de las nuevas tecnologías digitales de la información y de las redes informáticas descentralizadas, de modo que el acceso a Internet por parte de aquéllos es menester compatibilizarlo con otros derechos e intereses legítimos, como sucede con los involucrados en las actividades

como el TEDH), como señala C. PAuner Chulvi, en «La libertad de información como límite al derecho a la protección de datos personales: la excepción periodística», Teoría y Realidad Constitucional, n. ${ }^{\circ}$ 36, 2015, p. 382.

84 El fallo de dicha Sentencia declara: «El artículo 6, apartado 1, de la Directiva 93/13/CEE del Consejo, de 5 de abril de 1993, sobre las cláusulas abusivas en los contratos celebrados con consumidores, debe interpretarse en el sentido de que se opone a una jurisprudencia nacional que limita en el tiempo los efectos restitutorios vinculados a la declaración del carácter abusivo, en el sentido del artículo 3, apartado 1, de dicha Directiva, de una cláusula contenida en un contrato celebrado con un consumidor por un profesional, circunscribiendo tales efectos restitutorios exclusivamente a las cantidades pagadas indebidamente en aplicación de tal cláusula con posterioridad al pronunciamiento de la resolución judicial mediante la que se declaró el carácter abusivo de la cláusula en cuestión». Apenas un mes después de ser dictada, el Gobierno ha aprobado el Real Decreto-ley 1/2017, de 20 de enero, de medidas urgentes de protección de consumidores en materia de cláusulas suelo, que viene a establecer un procedimiento de reclamación previa de los consumidores afectados ante las entidades de crédito «como consecuencia de los últimos pronunciamientos judiciales en materia de cláusulas suelo y, en particular, la sentencia del Tribunal de Justicia de la Unión Europea de 21 de diciembre de 2016, en los asuntos acumulados C-154/15, C-307/15 y C-308/15». 
relacionadas con la propiedad intelectual. De hecho, incluso recientes modificaciones normativas se han revelado deficientes para efectuar una conciliación y una ponderación de esos derechos e intereses en juego (y eventualmente en conflicto). Así, en el ámbito de ese dinámico sector, vale la pena mencionar la Ley 21/2014, de 4 de noviembre, por la que se modifica el texto refundido de la Ley de Propiedad Intelectual, aprobado por Real Decreto Legislativo 1/1996, de 12 de abril, y la Ley 1/2000, de 7 de enero, de Enjuiciamiento Civil, cuyo Exposición de motivos justifica la modificación «en cumplimiento de la reciente jurisprudencia del TJUE».

Al hilo de esto último, efectivamente, debe recalcarse que ha sobrevenido una condena aún más reciente pronunciada contra España por el TJUE, a saber, la Sentencia de 9 de junio de 2016 (caso EGEDA y otros, asunto C-470/14) ( $^{85}$, en la que se concluyó que la Directiva 2001/29/CE del Parlamento Europeo y del Consejo, de 22 de mayo de 2001, relativa a la armonización de determinados aspectos de los derechos de autor y derechos afines a los derechos de autor en la sociedad de la información [concretamente, su art. 5.2.b)], «debe interpretarse en el sentido de que se opone a un sistema de compensación equitativa por copia privada que, como el controvertido en el litigio principal, está sufragado con cargo a los Presupuestos Generales del Estado, sin que resulte por ello posible asegurar que el coste de dicha compensación equitativa sea soportado por los usuarios de copias privadas»; lo cual permite garantizar asimismo la percepción efectiva destinada a indemnizar a los titulares de los derechos ${ }^{86}$.

\section{REFLEXIONES FINALES: LA EJECUCIÓN DE SENTENCIAS DEL TJUE COMO OPTIMIZACION DEL ORDENAMIENTO JURÍDICO INTERNO}

Llegados a este punto, conviene recalcar que la ejecución de sentencias del TJUE debe ser asumida con naturalidad como parte de ese principio de sujeción a la Constitución y al resto del ordenamiento jurídico que afecta a la ciudadanía y a todos los poderes públicos nacionales (art. 9.1 en conexión con art. $93 \mathrm{CE}$ ).

Respecto a la concreta responsabilidad de los poderes públicos (art. 9.3 CE), un ejemplo de cómo puede confluir la acción de las autoridades legislativas, ejecutivas y judiciales en la ejecución de una sentencia del TJUE se recoge en la Ley

85 El asunto tiene su origen en la cuestión prejudicial planteada por el TS mediante auto de 10 de septiembre de 2014 en el procedimiento entre Entidad de Gestión de Derechos de los Productores Audiovisuales (EGEDA), Derechos de Autor de Medios Audiovisuales (DAMA), Visual Entidad de Gestión de Artistas Plásticos (VEGAP) por un parte y, por otra, Administración del Estado y Asociación Multisectorial de Empresas de la Electrónica, las Tecnologías de la Información y la Comunicación, de las Telecomunicaciones y de los Contenidos Digitales (Ametic).

86 Véanse, en este sentido, las SSTJUE de 16 de junio de 2011 (Stichting de Thuiskopie, asunto C-462/09, apartado 34) y de 11 de julio de 2013 (Amazon.com International Sales y otros, C-521/11, apartado 57). 
6/1999, de 16 de marzo, sobre concesión de un crédito extraordinario, por importe de 196.505.344 pesetas, para el pago de indemnizaciones establecidas en la sentencia firme, dictada en el recurso contencioso-administrativo número 5/234/1996, a favor de Médicos Especialistas en Estomatología. Concretamente, sobre la base de la interpretación dada por el TJUE a las Directivas sobre la materia (si bien no se identifica con claridad el pronunciamiento concreto en la Exposición de motivos de dicha Ley), se concluye que la Administración española las ha incumplido y, por tanto, para atender las indemnizaciones impuestas por la Justicia nacional con apoyo en la asunción de dicha jurisprudencia y normativa europeas, se ha de hacer efectiva la reserva de ley correspondiente.

Desde la perspectiva de las autoridades judiciales, la ejecución de sentencias del TJUE no sólo se favorece con las cuestiones prejudiciales, sino también a través de normativa competencial específica, como la recogida en la Ley 12/1998, de 28 de abril, por la que se modifica la Ley 13/1994, de 1 de junio, de Autonomía del Banco de España ${ }^{87}$. A este respecto, en el nivel más elevado, el diálogo del TC con el TJUE (y con el TEDH) no constituye una mera preocupación académica, sino un reto para la praxis judicial y, en suma, para la protección de los derechos fundamentales ${ }^{88}$. De hecho, al margen de la controversia suscitada por episodios referentes a los diversos niveles de protección a cuenta del conocido «caso Melloni» ${ }^{89}$, la jurisprudencia constitucional pone de manifiesto otros supuestos de concurrencia ${ }^{90}$.

87 Su art. 2.3 establece que «sin perjuicio de la competencia del Tribunal de Justicia de la Comunidad Europea, la Sala de lo Contencioso-administrativo de la Audiencia Nacional conocerá en única instancia de los recursos contra actos no susceptibles de recurso administrativo dictados por el Banco de España y contra las resoluciones del Ministro de Economía y Hacienda que resuelvan recursos ordinarios contra actos dictados por el Banco de España.

88 Pueden verse los trabajos de G. C. Rodríguez Iglesias, y A. Valle Gálvez, «El Derecho comunitario y las relaciones entre el Tribunal de Justicia de las Comunidades Europeas, el Tribunal Europeo de Derechos Humanos y los tribunales constitucionales nacionales», RDCE, n. ${ }^{\circ} 2,1997$, pp. 329-376, así como de J. I. Ugartemendia Eceizabarrena, «QQuién es el juez de los derechos fundamentales frente a la Ley en el ámbito interno de aplicación del Derecho comunitario? (Reflexiones sobre el control iusfundamental del Derecho interno a la luz de la recepción nacional de los derechos fundamentales de la Unión Europea», Teoría y Realidad Constitucional, n. ${ }^{\circ} 20,2007$, pp. 401-433.

89 Las Conclusiones del Abogado General Sr. Yves Bot, presentadas el 2 de octubre de 2012 en ese asunto C-399/11 (Melloni), abogan por una interpretación restrictiva del artículo 53 de la Carta de los Derechos Fundamentales (apartados 89 a 102), rechazando asimilarlo «a una cláusula de estándar mínimo de protección, característica de los instrumentos internacionales de protección de los derechos humanos, como la que contiene el artículo 53 del CEDH. De ser así, la Carta impondría un estándar mínimo, y permitiría que los Estados miembros aplicaran el estándar de protección más elevado que derivara de su Constitución, evitando así una regresión del grado de protección de los derechos fundamentales» (apartado 91). Y la rechaza en aras del principio de principio de primacía del Derecho de la Unión, ya que la interpretación maximalista «conduciría a atribuir la prioridad en cada caso específico a la norma jurídica que concediera el grado de protección más alto al derecho fundamental considerado. En algunos casos se reconocería así la preeminencia de las Constituciones nacionales sobre el Derecho de la Unión» (apartado 97).

90 Véase la STC 20/2012, de 16 de febrero, con origen en la cuestión de inconstitucionalidad 647 2004 planteada por el Juzgado de Primera Instancia n. ${ }^{\circ} 8$ de A Coruña en relación con el apartado segundo del art. 35.Siete de la Ley 53/2002, de 30 de diciembre, de medidas fiscales, administrativas y del orden 
Por otra parte, como se ha visto a lo largo del presente estudio, la ejecución de sentencias del TJUE, como parte del más amplio cumplimiento de las obligaciones comunitarias europeas, no sólo reviste complejidad jurídica, sino que además tiene un indudable impacto político y económico. De hecho, tanto la disposición adicional segunda de la LO 2/2012, de 27 de abril, de Estabilidad Presupuestaria y Sostenibilidad Financiera, como su desarrollo mediante el Real Decreto $515 / 2013$, de 5 de julio, por el que se regulan los criterios y el procedimiento para determinar y repercutir las responsabilidades por incumplimiento del Derecho de la UE ${ }^{91}$, fueron impugnados por el Gobierno de Canarias, respectivamente a través de un recurso de inconstitucionalidad (desestimado por STC 215/2014, de 18 de diciembre) y de un conflicto positivo de competencia (desestimado por STC 31/2016, de 18 de febrero ${ }^{92}$. Por lo demás, ese sistema de repercusión ad intra de la responsabilidad por incumplimientos del Derecho de la UE ya contaba con antecedentes que fueron objeto de controversia ante la jurisdicción constitucional ${ }^{93}$.

En estas condiciones, es obvio que la ejecución de las sentencias del TJUE, como parte de la natural asunción de las obligaciones comunitarias y de la incorporación del Derecho de la UE como elemento integrante del ordenamiento

social. La conclusión fue confirmatoria de la constitucionalidad de dicho precepto legal, que supedita la tramitación de las demandas presentadas por personas jurídicas con ánimo de lucro sujetas al impuesto sobre sociedades y que superen una determinada facturación anual al abono de la tasa por el ejercicio de la potestad jurisdiccional en el orden civil. Tras apoyar la conclusión desestimatoria en la propia jurisprudencia constitucional, el FJ 10 dice argumentarla asimismo con soporte en las jurisprudencias del TEDH y del TJUE, con citas explícitas en pronunciamientos concretos de ambos tribunales europeos.

91 Como ilustración de la aplicación reciente de ese procedimiento de repercusión de responsabilidades establecido en el Real Decreto 515/2013 puede acudirse al BOE n. ${ }^{\circ} 281$ de 21 de noviembre de 2016, en el aparecen diversas Resoluciones de 3 de noviembre de 2016 del Fondo Español de Garantía Agraria por las que se publican los Acuerdos correspondientes del Consejo de Ministros de 7 de octubre de 2016 mediante los que se aprueba la terminación del procedimiento de repercusión iniciado a diversas Comunidades Autónomas (Castilla-La Mancha, Navarra, Canarias, Madrid, Illes Balears, Comunitat Valenciana). En el plano doctrinal, léase D. ORDóÑEz Solis, «La ejecución forzosa de la recuperación y de la devolución de las ayudas de estado en la Unión Europea y en España», Gaceta jurídica de la Unión Europea y de la competencia, n. ${ }^{\circ}$ 9, 2009, pp. 75-96.

92 El Real Decreto 515/2013, de 5 de julio, también fue objeto de impugnación mediante recurso contencioso-administrativo (n. ${ }^{\circ}$ 346/2013) interpuesto por la Diputación Foral de Bizkaia, recurso que ha sido desestimado por la Sala de lo Contencioso-Administrativo del TS mediante Sentencia de 26 de junio de 2016 remitiéndose básicamente a la STC 215/2014, de 18 de diciembre, que «ha rechazado que dicha norma reglamentaria suponga una vulneración de la autonomía financiera y fiscal reconocida a dicha Comunidad Autónoma, que goza de un régimen fiscal singular, con la exposición de los siguientes razonamientos jurídicos, que resultan aplicables mutatis mutandis para la resolución de este proceso».

93 Así sucedió con los sistemas establecidos en la LO 5/2001, de 13 de diciembre, complementaria a Ley general de estabilidad presupuestaria, y en la Ley 18/2001, de 12 de diciembre, general de estabilidad presupuestaria (SSTC 188/2011, de 23 de noviembre, FJ 9; 196/2011, de 13 de diciembre, FJ 11; 198/2011, de 13 de diciembre, FJ 15). Y ha contado asimismo con ulteriores desarrollos polémicos como los introducidos en Ley 38/2003, de 17 de noviembre, general de subvenciones (STC 130/2013, de 4 de junio, FJ 9) mediante Real Decreto-ley $7 / 2013$, de 28 de junio, de medidas urgentes de naturaleza tributaria, presupuestaria y de fomento de la investigación, el desarrollo y la innovación (declarado parcialmente inconstitucional por STC 70/2016, de 14 de abril, FJ 7). 
interno, no siempre está exenta de complicaciones. En este sentido, la mayor parte de las veces la ejecución es sencilla, mientras que en otros la misma revela aspectos deficitarios, ya sea por el modo en que las autoridades nacionales proceden a la ejecución (lo que aboca a veces a un nuevo procedimiento de infracción con ulterior condena), ya sea por el self-restraint o las limitaciones del cometido atribuido al TJUE (por ejemplo, en materia de vivienda), ya sea por la propia complejidad y el alcance de la cuestión sobre la que se ha pronunciado (piénsese en la STJUE Ana de Diego Porras y Ministerio de Defensa, de 14 de septiembre de 2016, sobre los interinos, y la creación incluso de un comité de expertos para esclarecer el modo de cumplirla o ejecutarla ${ }^{94}$ ).

Muchas de estas sentencias del TJUE han tenido un gran impacto mediático, como sucedió con la STJUE Aziz de 14 de marzo de 2013 y la STJUE Gutiérrez Naranjo y otros de 21 de diciembre de 2016, o la recién citada STJUE Ana de Diego Porras y Ministerio de Defensa de 14 de septiembre de 2016; una sentencia, esta última, cuya complejidad se ha visto incrementada por la adopción de otras del TJUE en ámbitos conexos ${ }^{95}$, por el modo de asumirla en España algún Tribunal Superior de Justicia ${ }^{96}$ y, adicionalmente, por la concurrencia de pronunciamientos recientes en la materia por parte de nuestra Jurisdicción Constitucional ${ }^{97}$.

94 Véase «Los expertos que analizan la sentencia de los interinos tendrán listo el informe a finales de diciembre», 23 de noviembre de 2016, en http://www.iustel.com/diario_del_derecho/noticia.asp?ref_iuste$1=1159746 \& u t m \_s o u r c e=D D \& u t m \_$medium $=$email\&nl $=1$ \&utm_campaign=23/11/2016 (visitado el 23 de noviembre de 2016): «La ministra de Empleo y Seguridad Social, Fátima Báñez, ha afirmado durante su turno de réplica en la Comisión de Seguimiento y Evaluación de los Acuerdos del Pacto de Toledo que el grupo de expertos que analiza la sentencia del Tribunal de Justicia Europeo (TJUE), que iguala los días por despido de interinos y fijos, tendrá el listo el informe 'profesional e independiente' a finales de diciembre (de 2016), recordando que el informe «no es vinculante pero es un informe independiente» para trabajar por el empleo de calidad en el país y para la competitividad de las empresas. La ministra ha señalado que el grupo de expertos, nombrados por los interlocutores sociales y el Gobierno, servirá también para trabajar hacia un futuro en el que «haya una mayor seguridad jurídica para las empresas y para los trabajadores». «Es compatible que las empresas tengan mayor seguridad jurídica con que los trabajadores tengan mayor protección social».

95 Léanse SSTJUE de fecha 14 de septiembre de 2016 dictadas en el caso María Elena Pérez López y Servicio Madrileño de Salud (asunto C-16/15) y en los casos Florentina Martínez Andrés y Servicio Vasco de Salud y Juan Carlos Castrejana López y Ayuntamiento de Vitoria-Gasteiz (asuntos acumulados C-184/15 y C-197/15).

96 Ha sido señaladamente el caso del TSJ del País Vasco (Sala de lo Social), mediante Sentencia n. ${ }^{\circ} 1962$ de 18 de octubre de 2016 (recurso de suplicación n. ${ }^{\circ}$ 1690/2016), en la que con apoyo en esa doctrina del TJUE sobre el caso Ana de Diego Porras se procede al reconocimiento de oficio, en el marco de un procedimiento de despido (en contrato temporal), de una indemnización de 20 días por año en supuestos de válida finalización de contrato por obra determinada. Una crítica a esta Sentencia del TSJ vasco en el diario económico Expansión, del 20 de octubre de 2016, en donde (p. 28) se habla de «revolución en el mercado laboral» por referencia a esa «primera sentencia que ya equipara el despido de un temporal con el de un fijo» encaminándonos hacia el «contrato único por la vía judicial», y se recoge la opinión desfavorable de F. DURÁN LóPEZ («Crónica de una sentencia anunciada»; en su artículo avanza que «esta sentencia, y las que vendrán, no van a refrenar los impulsos progresistas ‘pro operario’ de los jueces»), así como (en p. 29) la de M. Godino Reyes («La imparable extensión de la indemnización de veinte días»; en su artículo critica «una función que corresponde realizar al legislador y no al juez»).

97 Por ejemplo, la STC 71/2016, de 14 de abril, que tiene su origen en la cuestión de inconstitucionalidad 389-2014 planteada por la Sala de lo Social del Tribunal Superior de Justicia de Canarias respecto de la disposición adicional quincuagésima séptima de la Ley 10/2012, de 29 de diciembre, de presupuestos 
En fin, para concluir, entendemos que el citado impacto mediático, en todo caso, más allá del debate político, debería ser aprovechado para seguir fortaleciendo la conciencia europea como parte de un sentimiento constitucional más profundo $^{98}$.

TITLE: The Enforcement of Judgments of the Court of Justice as a Shared Constitutional Responsibility: Lights and Shadows

ABSTRACT: This paper tackles the enforcement of judgments of the Court of Justice as the most emblematic aspect of the constitutional dimension of the European Union, in line with the principle of loyalty or sincere cooperation in the fulfillment of European obligations. From this point of view, the State's international responsibility in implementing the judgments of the Court of Justice is also analyzed through the principle of responsibility of all public authorities. In this sense, the essay analyzes the virtues and complexities of the Spanish constitutional practice regarding the enforcement of judgments of the Luxembourg Court carried out not only by the national courts but also by other public authorities (executive and legislative ones) at both state and regional levels. In conclusion, beyond the media impact of some European judgments, the emphasis is placed on their actual enforcement as a factor to optimize the domestic legal order and, above all, as an essential element to improve the degree of Europeanism of citizenship.

RESUMEN: El presente trabajo aborda la ejecución de sentencias del Tribunal de Justicia como exponente más emblemático de la dimensión constitucional de la Unión Europea en coherencia con el principio de lealtad o cooperación sincera en el cumplimiento de las obligaciones europeas. Desde este punto de vista, la responsabilidad internacional estatal al implementar las sentencias del Tribunal de Justicia es analizada asimismo a través del principio de responsabilidad de todos los poderes públicos. En este sentido, el artículo analiza las virtudes y las complejidades de la práctica constitucional española relativa a la ejecución de sentencias del Tribunal de Luxemburgo llevada a cabo no sólo por los órganos jurisdiccionales nacionales, sino también por las demás autoridades públicas (ejecutivas y legislativas) a nivel estatal y regional. En conclusión, más allá del impacto mediático de algunas sentencias europeas, se pone el énfasis en su ejecución como factor de optimización del ordenamiento jurídico interno y, sobre todo, como elemento esencial de mejora del grado de europeísmo de la ciudadanía.

KEY WORDS: Sincere cooperation, judicial feed-back, enforcement by executive and legislative authorities, multi-level constitutionalism, europeanism.

Palabras Clave: Cooperación sincera, retroalimentación judicial, ejecución por los poderes ejecutivo $y$ legislativo, constitucionalismo multinivel, europeísmo.

FECHA DE RECEPCIÓN: 08.01.2016 FeCHA DE ACEPTACIÓN: 01.02.2017

generales de la Comunidad Autónoma de Canarias. En ella se declara la nulidad del precepto legal controvertido, que introducía una reducción de trabajo para el personal laboral indefinido y temporal (véase, con relación a la jurisprudencia del TJUE, el FJ 5, en donde se citan Sentencias de 13 de septiembre de 2007, asunto del Cerro Alonso; de 22 de diciembre de 2010, asunto Gavieiro Gavieiro e Iglesias Torres; o de 9 julio de 2015, asunto Regojo Dans; así como Auto del TJUE de 9 de febrero de 2012, asunto Lorenzo Martínez).

98 J. Tajadura Tejada, «El sentimiento constitucional», Claves de la razón práctica, n. ${ }^{\circ}$ 77, 1997, pp. 72-74. 
